\title{
La vajilla de barniz negro en Empúries y la Layetania. Origen y técnica de producción a partir de su caracterización arqueométrica*
}

\author{
Black Gloss pottery from Empúries and Laietania. \\ Origin and production techniques from its \\ archaeometric characterization
}

\author{
Marisol Madrid i Fernández \\ Universitat de Barcelona \\ mmadrid@ub.edu \\ ORCID iD: https://orcid.org/0000-0003-3888-7244 \\ Alejandro G. Sinner \\ University of Victoria \\ agsinner@uvic.ca \\ ORCID iD: https://orcid.org/0000-0002-5816-5794
}

Enviado: 21-05-2019. Aceptado: 16-09-2019. Publicado online: 22-03-2021

Cómo citar este artículo / Citation: Madrid i Fernández, M. y Sinner, A. G. (2021). "La vajilla de barniz negro en Empúries y la Layetania. Origen y técnica de producción a partir de su caracterización arqueométrica". Archivo Español de Arqueología, 94, e01. DOI: https://doi.org/10.3989/aespa.094.021.01

RESUMEN: El objetivo de este artículo es aportar nuevos datos sobre la cerámica de barniz negro tardorrepublicana distribuida en Empúries, que nos permitan avanzar en su origen, así como profundizar en aspectos relacionados con su proceso de fabricación. Para ello, y en el marco de un proyecto más amplio que incluye el análisis de diversos yacimientos de la costa catalana, se ha procedido a la caracterización arqueométrica de una muestra que incluye cerámicas clasificadas arqueológicamente como imitaciones de Campaniense A, Campaniense A, Etruscas, Cales antiguo, Cales medio y Cales tardío. Los resultados muestran que todos los individuos a priori calenos se corresponderían en realidad con producciones etrusco/laciales. Por otro lado, aquellas cerámicas clasificadas como imitaciones de Campaniense A, presentan características composicionales similares al taller de Rosas, de cronología anterior (mitad del siglo IV - finales del siglo III a. C.). En relación con las cerámicas etruscas, se puede proponer Arezzo o Volterra como posibles áreas de origen; y, finalmente, la cerámica clasificada como Campaniense A se correspondería con la fabricada en Nápoles.

\footnotetext{
* La realización de este artículo no habría sido posible sin la generosa financiación de la University of Victoria a través de la concesión de una Internal Research Grant (IRCPG) para financiar el proyecto Commercial Circuits and Cultural Contacts between Central Italy and Spain: An Archaeometrical Approach.

Agradecemos a la redacción de la revista y a los revisores de este articulo sus comentarios, los cuales han permitido mejorar la comprensión y la calidad del mismo.
} 
Palabras clave: Campaniense A; Cales antiguo; Cales medio; Cales tardío; Hispania; Fluorescencia de Rayos X (FRX); Difracción de Rayos X (DRX); Microscopía Electrónica de Barrido (MEB).

ABSTRACT: This article aims to contribute new data on Late Republican Black Gloss pottery distributed in Empúries, which will enable us to gain further knowledge as regards both its origin and certain aspects related to the manufacturing process. For this purpose, and within the wider framework of a project including the analysis of several sites in coastal Catalonia, the archaeometric characterization of a range of wares, including samples archaeologically classified as Campanian A imitations, Campanian A, Etruscan, Early Cales, Middle Cales and Late Cales, were performed. The results show that all the sherds a priori classified as Cales in fact correspond to wares produced in Etruria/Latium. Furthermore, those wares identified as Campanian A imitations display compositional characteristics similar to those from the Rosas workshop, of earlier date (mid 4th to late 3rd century BC). As regards the Etruscan wares, Arezzo and Volterra can be proposed as possible areas of origin; finally, the pottery classified as Campanian A belongs to the wares produced in Naples.

Keywords: Campanian A; Early Cales; Middle Cales; Late Cales; Hispania; X-ray fluorescence (XRF); X-ray diffraction (XRD); Scanning Electronic Microscopy (SEM).

Copyright: $\left({ }^{\circ} 2021\right.$ CSIC. Este es un artículo de acceso abierto distribuido bajo los términos de la licencia de uso y distribución Creative Commons Reconocimiento 4.0 Internacional (CC BY 4.0).

\section{INTRODUCCIÓN Y OBJETIVOS}

Empúries destaca desde la fundación de la Neàpolis, hacia finales del siglo VI / inicios del siglo V a. C. (Sanmartí et al., 1986; Aquilué et al., 2009), como un centro receptor de bienes de consumo procedentes de todo el Mediterráneo y como uno de los principales centros de redistribución hacia el resto de la Península Ibérica, especialmente hacia el nordeste y Levante peninsular. Ya en el siglo VI a. C. se observa en la ciudad griega la presencia de cerámica de importación, como por ejemplo la producción ática de figuras rojas, de la cual se han documentado una gran parte de los tipos y formas conocidas (Miró, 1998, p. 137). Sin embargo, son los dos últimos siglos anteriores al cambio de era, los que han proporcionado una mayor abundancia de materiales, especialmente cerámica procedente de la península itálica. Este incremento, claramente documentado en el registro arqueológico, estaría relacionado con la presencia del ejército romano en Hispania. Emporion fue uno de los puntos fuertes de los ejércitos de Escipión primero (218-206 a. C.) (Livio 21.60.3-4; Polibio 3.76.2.) y de Catón después (Livio 34.11), especialmente durante los momentos más álgidos de las revueltas indígenas (197-195 a. C.). Además, es importante destacar el hallazgo de lo que parece ser un establecimiento militar de grandes dimensiones y que ha sido fechado por sus excavadores en torno a los decenios centrales del siglo II a. C. Este recinto demuestra la importancia logística y militar que la ciudad de Emporion continuaba teniendo para la administración romana a mediados de dicha centuria (Tremoleda, Santos y Castanyer, 2016). Este panorama, junto con la progresiva integración de los territorios indigetes (Nolla, Palahí y Vivo, 2010) y del conjunto del nordeste peninsular (Olesti, 2010) en la órbita romana, explica la intensificación de la comunicación marítima entre Italia y esta zona de la península ibérica durante la segunda mitad del siglo II a. C. El resultado es la llegada masiva de productos de toda Italia, especialmente aceite, vino y vajilla de mesa, tal y como se documenta arqueológicamente en muchos de los yacimientos del litoral catalán (Asensio, 2010; Stannard y Sinner, 2014; Carreras Monfort et al., 2016). Es en este momento histórico (siglos II-I a. C.) en el que se enmarca el trabajo que aquí presentamos.

La colonización del Mediterráneo occidental por Roma propició una importante expansión de la economía de los pueblos indígenas del nordeste peninsular, abriéndoles los mercados del resto del Imperio (Temin, 2013; Tchernia, 2016). A medida que disciplinas como la arqueometría y la arqueología -tanto terrestre 


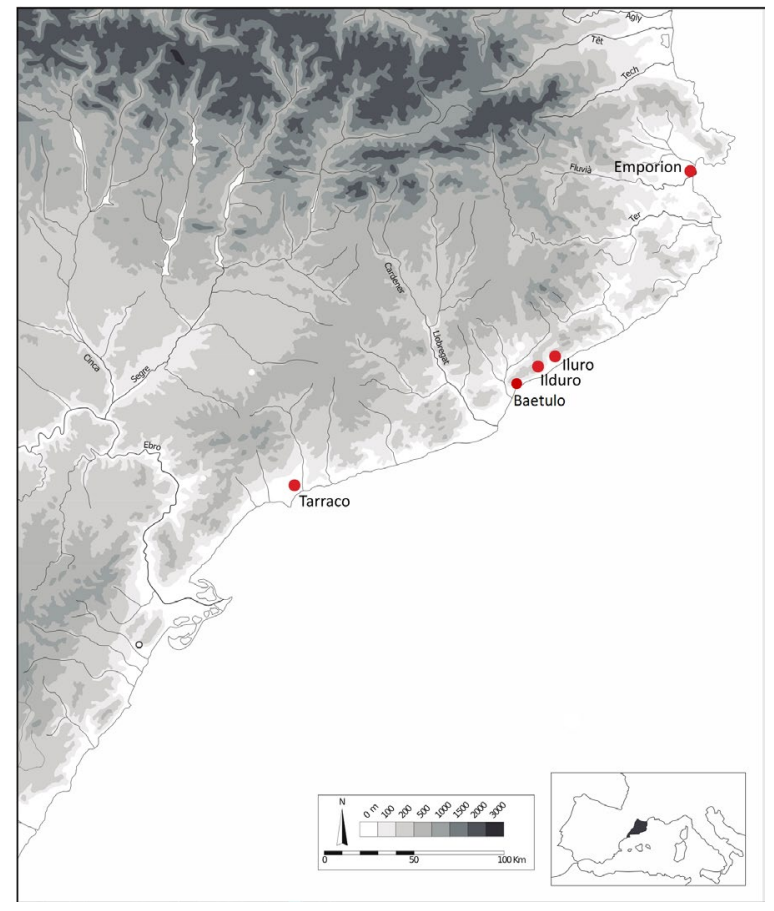

Figura 1. Mapa con la localización de Empúries y otros yacimientos antiguos de la costa catalana citados en el texto (elaboración propia).

como subacuática- aportan nuevos datos parece necesaria la reinterpretación de los distintos circuitos, a través de los cuales se organizó el comercio durante la República romana tardía y los inicios del Imperio en el Mediterráneo occidental. Como se verá a lo largo de este trabajo, la distribución de la vajilla de barniz negro tardorrepublicana durante este período en lugares tan cercanos como Empúries, Ilduro e Iluro (Fig. 1), y a diferencia de lo que se ha creído hasta su reciente estudio arqueométrico, procede en su mayoría de áreas distintas, obedeciendo probablemente a circuitos comerciales o redes de redistribución diferentes si tenemos presente el origen de dichas producciones.

En este sentido, cabe remarcar que resulta imposible inferir la proveniencia de ciertas categorías cerámicas, entre ellas las producciones de barniz negro, únicamente a partir de criterios arqueológicos. Ello se debe a que, intencionadamente, los ceramistas trataron de fabricar un producto de características similares, tanto a nivel morfológico como en términos de pasta y barniz.

Desde un punto de vista arqueológico, la vajilla de barniz negro ha sido objeto de numerosos estudios con el fin de establecer una tipología y una cronología básicas, basadas en la forma y estilo de los vasos (para estudios fundamentales ver Lamboglia, 1952, 1960; Morel, 1981, 1990; Morel et al., 1985; Pedroni, 1986). Sin embargo, la heterogeneidad morfológica, junto con un gran número de talleres involucrados en la fabricación de esta cerámica (Olcese, 2012, 2013), no encaja necesariamente con la clasificación en tres categorías A, B y C, definidas como "preliminares" por Lamboglia en 1952, y que todavía se encuentran en uso hoy en día, ampliadas con el estudio pormenorizado sobre Cales que dio lugar a una periodización de la producción de este centro, utilizada especialmente en la península ibérica, lugar que se propone como principal destinatario de los productos del centro campano (Pedroni, 2001). Estas categorías se basaron, como ya indica Pedroni (1986, p. 9) en la apariencia de la pasta y el barniz de cada una de ellas: roja para la Campaniense A, beige para la Campaniense B, y gris para la Campaniense C. Estas características corresponden al uso de unas arcillas con un bajo contenido en calcio para el cuerpo cerámico en el caso de la primera, y unas arcillas ricas en contenido de calcio para la elaboración de la Campaniense $\mathrm{B}$ y C, aunque la preparación de las pastas puede variar de un taller a otro (Picon, Vichy y Chapotat, 1971; Morel y Picon, 1994). Antes de la cocción, el proceso se completa aplicando sobre el cuerpo cerámico una delgada capa de barbotina de tamaño de grano muy fino, preparada a partir de una arcilla illítica, no calcárea, con el fin de obtener un barniz brillante. Los estudios centrados en la naturaleza del barniz negro de las producciones áticas (Maniatis, Aloupi y Stalios, 1993), es decir en las arcillas utilizadas para su preparación (Chaviara y Aloupi, 2016), han demostrado, a diferencia de la asunción tradicional, que las arcillas utilizadas para la preparación de los barnices son distintas de aquellas utilizadas para el cuerpo cerámico. Finalmente, como ya explicaron Maggetti et al. (1981, pp. 3-4) y confirmado por estudios recientes (Aloupi, 2008; Lühl et al., 2014; Chaviara y Aloupi, 2016, pp. 510-511), un proceso de cocción exitoso requiere unas condiciones ORO (oxidante-reductora-oxidante) en un rango de temperatura máxima de $900-950{ }^{\circ} \mathrm{C}$. Este proceso comporta una fase prolongada en atmósfera oxidante, seguida de una fase de reducción con una simultánea reducción de la temperatura hasta $825^{\circ} \mathrm{C}$; finalmente, una nueva etapa de oxidación durante el enfriamiento del horno proporcionará el producto final deseado. Una de las mejores explicaciones sobre este proceso, centrado ya en las producciones de barniz negro tardorrepublicanas fabricadas en la península itálica, se puede encontrar en el artículo publicado por Gliozzo y colaboradores, donde también se proporciona una amplia selección de publicaciones sobre la aplicación de barnices (Gliozzo et al., 2004, pp. 227-228).

Es importante conocer la zona de proveniencia de esta vajilla ya que se transportaba como cargamento secundario de una carga principal, en muchas ocasio- 
nes vino, en los navíos de grandes dimensiones que cubrían las rutas entre los principales puertos del Mediterráneo (Principal y Ribera, 2013, p. 53). El patrón parece haber sido el de un comercio primario y de larga distancia entre puertos principales como Ostia, Massalia, Empúries y Carthago Nova, los cuales a su vez alimentaban unas redes de redistribución secundarias, por mar y por tierra (Nieto, 1988, 1997).

En estas circunstancias, la cerámica de barniz negro llegó a la península ibérica de manera abundante a partir del siglo II a. C., y aunque ha sido objeto de numerosos estudios arqueológicos con el fin de clasificarla tipológicamente y cronológicamente (Sanmarti-Grego, 1978; Zamora, 1995; Sanmarti et al., 1996; Aquilué, García y Guitart, 2000; Jiménez 2000, 2002; Marín y Ribera, 2001; Principal y Ribera, 2013; Vivar, 2013; Palencia y Rodríguez, 2014; entre otros), prácticamente no existen estudios arqueométricos. Tan solo dos estudios llevados a cabo por Picon en colaboración con otros autores, han incorporado técnicas analíticas para la investigación sobre cerámicas de barniz negro. El primero, centrado en la diferenciación de la composición química de la cerámica Campaniense etrusca y aquella originaria de la Campania, utiliza individuos de la Galia y de la península ibérica. En este último caso, se indica que 16 de los ejemplares utilizados proceden, principalmente, de Empúries, sin proporcionar más datos al respecto (Morel y Picon, 1994, p. 24). El segundo se llevó a cabo en el yacimiento de La Loba (Andalucía) (Picon y Thirion-Merle, 2002). De acuerdo con estos estudios, Cales y Etruria (tipo B de Cosa) serían el origen de las cerámicas de Empúries. En La Loba, los altos niveles de alteración de la cerámica debido al contexto minero en el que se recuperaron dificultaron la identificación de su origen. A pesar de esta limitación, finalmente se sugirió un origen en la zona de la Campania y en Etruria (diferente del tipo B de Cosa) para los materiales examinados. Lamentablemente, en ninguno de los dos casos, se dan detalles sobre las cerámicas analizadas, ni a nivel morfológico ni tampoco tipológico.

Muy distinta es la situación en la que se encuentra la investigación sobre el barniz negro tardorrepublicano (o Campaniense) fuera de la península, donde destacan los estudios arqueométricos realizados en la propia península itálica, tanto en centros productores como centros de consumo. Un estado de la cuestión detallado fue publicado recientemente por nosotros mismos en el marco del estudio arqueométrico de barniz negro tardorrepublicano procedentes de los yacimientos de Ilduro e Iluro (Madrid y Sinner, 2019, con bibliografía).

Con el objetivo de mejorar nuestra comprensión sobre los circuitos comerciales que suplían y facilitaban el intercambio de productos entre el NE peninsular e Italia, presentamos el estudio de la vajilla de barniz negro tardorrepublicana documentada en Empúries a partir de su caracterización arqueométrica. Este trabajo se enmarca en un proyecto más amplio que incluye las dos ciudades romanas más importantes de la costa catalana, como son Empúries y Tarragona -actualmente en fase de análisis- así como de otras ciudades intermedias, como son Ilduro e Iluro, recientemente publicados (Madrid y Sinner, 2019), y Baetulo (Badalona), Iesso (Guissona) y el Camp de les Lloses (Tona, Vic) -también en proceso de análisis-. El estudio ha sido estructurado de acuerdo con un muestreo multifásico (Buxeda y Madrid, 2016, p. 20). En la primera fase, se ha llevado a cabo la caracterización química por Fluorescencia de Rayos X (en adelante FRX), y la mineralógica por Difracción de Rayos X (en adelante DRX). En la siguiente fase, una submuestra ha sido caracterizada microestructuralmente por medio de Microscopía Electrónica de Barrido (en adelante MEB), gracias a lo que se determinó el estadio de vitrificación de la matriz y del barniz.

De cara a lograr uno de los principales objetivos de este estudio, la identificación de los grupos cerámicos composicionalmente significativos presentes en la muestra, el tratamiento estadístico de los datos químicos se ha realizado juntamente con los datos obtenidos recientemente en Ilduro e Iluro, que comprenden las mismas clases cerámicas, en cuanto a clasificación arqueológica, y los contextos de los que proceden presentan una cronología similar (siglos II-I a. C.). También se han considerado conjuntamente para el estudio de proveniencia $-u$ origen- así como para el contraste con la base de datos del ARQUB que incluye, entre otros, materiales de barniz negro itálicos procedentes de la ciudad romana de Cosa (Italia) (Madrid y Buxeda, 2013). En el caso de Ilduro e Iluro se observaron diferencias en los patrones de distribución entre estos yacimientos y la ciudad de Cosa, lo que nos hizo sugerir circuitos comerciales distintos a través de los cuales el barniz negro tardorrepublicano se distribuyó en los diferentes centros de consumo, dentro y fuera de la península itálica (Madrid y Sinner, 2019). Para los estudios de proveniencia también se han tenido en cuenta los resultados analíticos publicados por otros autores que, especialmente desde inicios de los años 80 del siglo pasado, han incorporado la arqueometría en los estudios arqueológicos relacionados con la producción y difusión del barniz negro tardorrepublicano. La mayor parte de esta investigación se ha llevado a cabo en la península itálica, tanto desde centros productores como desde centros de consumo, permitiendo un progreso considerable en el complejo mundo de la cerámica de barniz negro que, a la vista de los resultados, debió implicar un gran número de talleres en 
la elaboración de esta cerámica (Olcese, 2012, 2013). En palabras de Gloria Olcese, una de las autoras más prolíficas en estudios cerámicos actualmente en la península itálica:

\begin{abstract}
El progreso de la investigación de laboratorio ha demostrado que la investigación arqueométrica sobre la cerámica es mucho más compleja de lo que se había previsto en los años 70/80 del siglo pasado, cuando se iniciaron estas investigaciones con el fin de que fueran difundidas y utilizadas por los arqueólogos (Olcese 2013, p. 47).
\end{abstract}

Un segundo objetivo es entender el proceso de fabricación de los distintos grupos cerámicos identificados a partir del análisis químico. Se pretende proporcionar información sobre aspectos técnicos relacionados con la temperatura de cocción equivalente (en adelante TCE), la microestructura desarrollada durante la cocción y las características del barniz; en este caso se pretende inferir la calidad y apariencia del mismo a partir de características como grosor, calidad de la barbotina utilizada para su elaboración, grado de vitrificación y su adherencia a la matriz cerámica.

Una vez finalizado el estudio propiamente arqueométrico, se volverá al estudio arqueológico para retroalimentarlo con los nuevos datos, cosa que nos permitirá, por un lado, comparar los resultados analíticos con la clasificación macroscópica realizada por los arqueólogos y observar, como tuvimos ocasión de comprobar para el caso de Ilduro e Iluro, hasta qué punto influye el proceso técnico seguido por los ceramistas en la antigüedad, en las desavenencias que se producen entre la clasificación arqueológica y arqueométrica (Madrid y Sinner, 2019). Así, arqueológicamente hablando, en el estudio llevado a cabo en Ilduro/Iluro, los individuos se agruparon en las siguientes categorías: Campaniense A, Etrusca, Cales antiguo, Cales medio y Cales tardío. En el caso que aquí nos ocupa, además de dichas categorías, se han añadido las siguientes: Cales antiguo e imitación de Campaniense A, para definir una producción con formas características de la Campaniense A itálica pero que presentaba un barniz que se desprendía con facilidad y cuya pasta tenía tonalidades de color beige claro. Por otro lado, el último paso será relacionar los grupos cerámicos identificados a partir de la investigación arqueométrica con sus contextos arqueológicos en Empúries.

\section{MATERIALES Y MÉTODOS}

Para cumplir con los objetivos planteados, se presenta el estudio arqueométrico de 29 individuos (Fig.
2). En la primera fase se llevó a cabo la caracterización química a través del análisis por FRX. La cuantificación se realizó con un espectrofotómetro AxiosmAX-Advanced PANalytical, con fuente de excitación de $\mathrm{Rh}$, utilizando una recta de calibración configurada con 56 patrones (Estándares Geológicos Internacionales). Se han determinado los siguientes elementos: $\mathrm{Na}_{2} \mathrm{O}, \mathrm{MgO}$, $\mathrm{Al}_{2} \mathrm{O}_{3}, \mathrm{SiO}_{2}, \mathrm{P}_{2} \mathrm{O}_{5}, \mathrm{~K} 2 \mathrm{O}, \mathrm{CaO}, \mathrm{TiO}_{2}, \mathrm{~V}, \mathrm{Cr}, \mathrm{MnO}, \mathrm{Fe}_{2} \mathrm{O}_{3}$ (como Fe total), Co, Ni, Cu, Zn, Ga, Rb, Sr, Y, Zr, Nb, Mo, Sn, Ba, Ce, W, Pb y Th. También se ha calculado la pérdida al fuego (PAF) a partir de calcinaciones de $0,3 \mathrm{~g}$ de espécimen seco a $950{ }^{\circ} \mathrm{C}$ durante $3 \mathrm{~h}$. La suma de las concentraciones de los elementos mayores, menores, traza y la PAF se encuentran en el rango de 98-102 \% (Fig. 3). Las concentraciones del Mo y del Sn se descartaron por imprecisiones analíticas; el W y el Co, debido a que el uso del molino de carburo de tungsteno que se utiliza para triturar y homogeneizar los individuos comporta el peligro de contaminaciones en estos elementos. De manera similar, en el caso presente, las concentraciones de $\mathrm{P}_{2} \mathrm{O}_{5}$ y $\mathrm{Pb}$ no se utilizaron en el tratamiento estadístico de los datos químicos porque algunos valores fueron considerados erráticos y algunos individuos quedaban fuera de sus grupos. Una descripción detallada de la precisión y exactitud ha sido ya publicada (Hein et al., 2002).

Por su parte, la composición mineralógica de estos 29 individuos ha sido estudiada mediante la DRX, utilizando el polvo de los especímenes previamente preparados. Las mediciones se realizaron utilizando un difractómetro de geometría Bragg-Brentano PANalytical X'Pert PRO MPD Alpha-1 (radi $=240$ $\mathrm{mm})$ utilizando la radiación $\mathrm{Cu} \mathrm{K} \alpha(\lambda=1,5418 \AA)$. La evaluación de las fases cristalinas presentes en cada espécimen analizado se realizó utilizando el paquete de software PANalytical X'Pert HighScore Plus que incluye el banco de datos del International Centre for Diffraction Data-Joint Committee of Powder Diffraction Standards, 2006 (ICDD-JCPDS).

Finalmente, de acuerdo con una estrategia de muestreo multifásico, una submuestra de individuos previamente analizados fue seleccionada para su estudio por MEB, de acuerdo con la estratificación revelada por los análisis (Buxeda y Madrid, 2016). Esta submuestra está compuesta de 15 individuos que serán indicados en la correspondiente sección técnica. Las observaciones se realizaron utilizando un JEOL JSM6510 en condiciones de alto vacío, a partir de fracturas frescas de secciones transversales de los individuos, con el fin de observar la microestructura, estimar el grado vitrificación de la matriz y el barniz.

Una descripción detallada de los procedimientos analíticos en FRX, DRX y MEB ha sido publicada con anterioridad (Madrid y Sinner, 2019). 


\section{LA MUESTRA Y SU CONTEXTO ARQUEOLÓGICO}

Los 29 individuos (de EMP111 a EMP139) que componen la muestra proceden en su totalidad de contextos arqueológicos correspondientes a excavaciones modernas, muchas de las cuales permanecen todavía inéditas (Fig. 2). Aun así, cabe señalar que la mayoría de los contextos se enmarcan en el período comprendi- do entre mitad del siglo II a. C. e inicios de la segunda mitad del siglo I a. C. (Castanyer et al., 2016), es decir la misma cronología que la propuesta para los contextos de donde proceden los individuos de Ilduro/Iluro, con el fin de poder comparar los resultados. A pesar de que la mayoría de los individuos analizados, así como los contextos de los que proceden, se encuentran todavía en fase de estudio, cabe destacar que la situación estratigráfica, así como un breve comentario sobre los indi-

\begin{tabular}{|c|c|c|c|c|c|c|}
\hline Ic & Yacimiento & $\begin{array}{l}\text { Clasificación } \\
\text { arqueológica }\end{array}$ & Tipología & $\begin{array}{c}\text { Color y brillo } \\
\text { del barniz }\end{array}$ & \begin{tabular}{|c|}
$\begin{array}{c}\text { Cronología de la } \\
\text { producción }\end{array}$ \\
\end{tabular} & $\begin{array}{c}\text { Cronología contexto } \\
\text { arqueológico }\end{array}$ \\
\hline EMP111 & $\begin{array}{l}\text { Neápolis (nivelación plaza } \\
\text { Serapis) }\end{array}$ & Imitación de Camp A & Lamb. 31 & Negro mate & ( 1 & $150-125$ a. C. \\
\hline EMP112 & $\begin{array}{l}\text { Neápolis (nivelación plaza } \\
\text { Serapis) }\end{array}$ & Imitación de Camp A & Lamb.36 & Negro mate & -- & $150-125$ a. C. \\
\hline EMP113 & $\begin{array}{l}\text { Neápolis (nivelación plaza } \\
\text { Serapis) }\end{array}$ & Imitación de Camp A & Lamb.36 & Negro mate & -- & $150-125$ a. C. \\
\hline EMP114 & $\begin{array}{l}\text { Neápolis (nivelación plaza } \\
\text { Serapis) }\end{array}$ & Imitación de Camp A & Lamb. 5/7 & Negro mate & -- & $150-125$ a. C. \\
\hline EMP115 & $\begin{array}{l}\text { Neápolis (nivelación plaza } \\
\text { Serapis) }\end{array}$ & Imitación de Camp A & Lamb. 36 & Negro (perdido) & -- & $150-125$ a. C. \\
\hline EMP116 & $\begin{array}{l}\text { Neápolis (nivelación plaza } \\
\text { Serapis) }\end{array}$ & Imitación de Camp A & Lamb. 31 & Negro mate & -- & $150-125$ a. C. \\
\hline EMP117 & Criptopórtico del fórum & Campaniense A tardía & $\mathrm{s} /$ forma & Negro mate & ca. $100-40$ a.C. & Final siglo I d. C. \\
\hline EMP118 & Criptopórtico del fórum & Campaniense A tardía & $\mathrm{s} /$ forma & Negro mate & ca. $100-40$ a.C. & Final siglo I d. C. \\
\hline EMP119 & Criptopórtico del fórum & Campaniense A tardía & s/forma & Negro mate & ca. $100-40$ a.C. & Final siglo I d. C. \\
\hline EMP120 & Criptopórtico del fórum & Campaniense A tardía & $\mathrm{s} /$ forma & Negro plateado & ca. $100-40$ a.C. & Final siglo I d. C. \\
\hline EMP121 & Neápolis (Trinchera Stoa) & Cales antiguo & F 2984 & Negro brillante & 200-130/120 a.C. & Mediados siglo II a. C. \\
\hline EMP122 & Neápolis (Trinchera Stoa) & Cales antiguo & $\mathrm{s} /$ forma & $\begin{array}{l}\text { Negro mate } \\
\text { intenso }\end{array}$ & 200-130/120 a.C. & Mediados siglo II a. C. \\
\hline EMP123 & Neápolis (Trinchera Stoa) & Cales antiguo & $\mathrm{s} /$ forma & $\begin{array}{l}\text { Negro mate } \\
\text { intenso }\end{array}$ & 200-130/120 a.C. & Mediados siglo II a. C. \\
\hline EMP124 & Obliteración bajo Insula 30 & Cales medio & Lamb. 5 & Negro mate & $\begin{array}{l}130 / 120-90 / 80 \\
\text { a.C. }\end{array}$ & $130-125$ a. C. \\
\hline EMP125 & Obliteración bajo Insula 30 & Cales medio & Lamb. 5 & Negro mate & $\begin{array}{l}130 / 120-90 / 80 \\
\text { a.C. }\end{array}$ & $130-125$ a. C. \\
\hline EMP126 & Silo 2150, zona Fórum & Cales tardío & Lamb. 5 & Negro mate & 90/80-40/20 a.C. & $40-30$ a. C. \\
\hline EMP127 & Silo 2150, zona Fórum & Cales tardío & Lamb. 6 & Negro mate & 90/80-40/20 a.C. & 40-30 a. C. \\
\hline EMP128 & Silo 2150, zona Fórum & Cales tardío & Lamb. 5 & Negro plateado & 90/80-40/20 a.C. & 40-30 a. C. \\
\hline EMP129 & Silo 2150, zona Fórum & Cales tardío & Lamb. 7 & $\begin{array}{l}\text { Negro mate } \\
\text { (zonas rojizas) }\end{array}$ & 90/80-40/20 a.C. & 40-30 a. C. \\
\hline EMP130 & St. Martí d’Empúries & Cales tardío & Lamb. 3 & Negro mate & 90/80-40/20 a.C. & Tardorromano \\
\hline EMP131 & Silo 2150, zona Fórum & Cales tardío & Lamb. 1 & Negro plateado & 90/80-40/20 a.C. & 40-30 a. C. \\
\hline EMP132 & Silo 2150, zona Fórum & Cales tardío & Lamb. 1 & $\begin{array}{l}\text { Negro mate } \\
\text { (marrón/negro) }\end{array}$ & 90/80-40/20 a.C. & 40-30 a. C. \\
\hline EMP133 & Silo 2150, zona Fórum & Cales tardío & Lamb. 1 & Negro mate & 90/80-40/20 a.C. & 40-30 a. C. \\
\hline EMP134 & St. Martí d'Empúries & Cales tardío & Lamb. 1 & Negro plateado & 90/80-40/20 a.C. & 130-125 a. C. \\
\hline EMP135 & Obliteración bajo Insula 30 & Etrusco & $\mathrm{s} /$ forma & Negro brillante & 150-50 a.C. & 130-125 a. C. \\
\hline EMP136 & $\begin{array}{l}\text { Neápolis (nivelación plaza } \\
\text { Serapis) }\end{array}$ & Etrusco & $\mathrm{s} /$ forma & $\begin{array}{l}\text { Negro brillante } \\
\text { (zonas rojizas) }\end{array}$ & $150-50$ a.C. & $150-125$ a. C. \\
\hline EMP137 & $\begin{array}{l}\text { Neápolis (nivelación plaza } \\
\text { Serapis) }\end{array}$ & Etrusco & Lamb. $5 / 7$ & $\begin{array}{l}\text { Negro mate } \\
\text { intenso }\end{array}$ & $150-50$ a.C. & $150-125$ a. C. \\
\hline EMP138 & $\begin{array}{l}\text { Neápolis (nivelación plaza } \\
\text { Serapis) }\end{array}$ & Etrusco & $\mathrm{s} /$ forma & $\begin{array}{l}\text { Negro mate } \\
\text { intenso }\end{array}$ & $150-50$ a.C. & $150-125$ a. C. \\
\hline EMP139 & Obliteración bajo Insula 30 & Etrusco & $\mathrm{s} /$ forma & $\begin{array}{l}\text { Negro mate } \\
\text { intenso }\end{array}$ & $150-50$ a.C. & $130-125$ a. C. \\
\hline
\end{tabular}

Figura 2. Individuos analizados en este estudio e información arqueológica (elaboración propia). 
viduos clasificados como imitaciones de Campaniense A fue publicado en su momento (Sanmartí, Castanyer y Tremoleda, 1989). El contexto de donde proceden nuestras muestras fue interpretado como un estrato de relleno, datado en el tercer cuarto del siglo II a. C. ${ }^{1}$ que nivelaría la plaza de Serapis creando un espacio a una cota más elevada.

También está publicada la excavación del relleno del silo 2150 de la que proceden siete de los individuos analizados en este estudio. Esta estructura formaba parte de un campo de silos existente en un momento anterior a la edificación del foro de la ciudad como tal (Aquilué et al., 2002, p. 11). Los materiales recuperados durante la excavación de este campo de silos, entre

1 Agradecemos a los investigadores de Empúries, Joaquim Tremoleda y Marta Santos, la información directa sobre todos los contextos arqueológicos de donde proceden las muestras analizadas en este estudio, así como su clasificación arqueológica y tipológica. ellos algunos de los que analizamos en este estudio, han sido publicados recientemente (Aquilué et al., 2010, pp. 41-43). Se trata, concretamente, de los ejemplares 11, 23 y 24 ilustrados en la figura 5 (Aquilué et al., 2010, p. 60) que se corresponden con nuestros ejemplares EMP132, EMP128 y EMP126, respectivamente.

\section{RESULTADOS QUÍMICOS}

Los resultados del análisis químico realizado por FRX (Fig. 3), es decir, las concentraciones elementales determinadas, corresponden a un caso especial propio de los datos composicionales (Aitchison, 1986; Buxeda, 1999; Martín-Fernández, Buxeda y Pawlowsky-Glahn, 2015; Buxeda, 2018). Debido a ello, para su tratamiento estadístico, los datos obtenidos han sido transformados utilizando la transformación clr en logaritmos de razón centrados, según

$$
\mathbf{x} \in \mathbb{S}^{d} \rightarrow \mathbf{z}=\ln \left(\frac{\mathbf{x}}{\mathrm{g}(\mathbf{x})}\right) \in \mathbb{R}^{d+1}
$$

\begin{tabular}{|c|c|c|c|c|c|c|c|c|c|c|c|c|c|c|c|c|c|c|c|c|c|c|c|c|c|c|c|c|c|c|}
\hline IC & & & $\mathrm{Al}_{2} \mathrm{O}_{3}$ & $\mathrm{O}_{2}$ & $\mathrm{O}_{5}$ & $\mathbf{K}_{2}$ & C & $\mathrm{O}_{2}$ & V & $\mathrm{Cr}$ & & $\mathrm{Fe}_{2} \mathrm{O}_{3}$ & Co & $\mathrm{Ni}$ & $\mathrm{Cu}$ & $\mathbf{Z n}$ & $\mathbf{G a}$ & $\mathbf{R b}$ & $\mathrm{Sr}$ & $\mathbf{Y}$ & $\mathbf{Z r}$ & $\mathbf{N b}$ & Mo & Sn & Ba & $\mathrm{Ce}$ & $\mathbf{W}$ & $\mathbf{P b}$ & $\mathbf{l n} \mathbf{P}$ & PAF \\
\hline MP111 & 38 & 1.9 & .85 & 87 & & 1.71 & 14.98 & 72 & 112 & 75 & 88 & 6.8 & 57 & 39 & 42 & 82 & 21 & 06 & 272 & 29 & 152 & 19 & & 1 & 561 & 95 & 94 & 27 & 4 & 4.13 \\
\hline & & & 01 & 2 & & & 11 & & 17 & 92 & & 28 & 8 & 3 & & & 2 & & & 2 & 79 & 0 & & & 61 & 33 & 43 & 29 & 72 & 2.63 \\
\hline & & & & & & & & & & & & & & & & & & & & 1 & & & & & & & 41 & 4 & & \\
\hline 1 & & 1 & .11 & 31 & & & & 32 & 91 & 74 & & & 8 & & & & 8 & & & 4 & & & & 4 & & 83 & & & & \\
\hline & & 2 & & 04 & & 4 & & 0.9 & 133 & 88 & & 04 & 3 & & & & 1 & 1 & & & & 20 & & 2 & 0 & & 40 & & & 2.1 \\
\hline & & & 45 & & & 7 & & & 11 & 75 & & 79 & 9 & & & & 1 & & & 32 & 34 & & & & & & 37 & 5 & & 47 \\
\hline & & & 7.48 & 18 & & 2.95 & & 36 & 122 & 87 & & 71 & 20 & & & & 1 & & & 39 & & 20 & & 2 & & & & & & 36 \\
\hline & & & 19 & 25 & 2 & 38 & & 0.72 & \begin{tabular}{|l|l|}
84 \\
\end{tabular} & 51 & & 51 & 16 & 7 & & & 1 & & & & & & &. & & & & 3 & 8 & 1.3 \\
\hline & & & 42 & 39 & 6 & 4 & & & \begin{tabular}{|l|l|}
79 \\
\end{tabular} & 68 & & 5.66 & & & 9 & 00 & 18 & & & 33 & 197 & & & 2 & & & 29 & 28 & 75 & 5.19 \\
\hline & & & 85 & 23 & & 4.75 & 64 & 71 & 77 & 38 & & 95 & 12 & 0 & 2 & 5 & 21 & 21 & & 10 & 51 & 52 & & 4 & & & 61 & & & 1. \\
\hline 12 & & 01 & 25 & 26 & 27 & 2.88 & 18 & 0.74 & 115 & 147 & & 37 & 19 & 5 & & 10 & 21 & 35 & 6 & 25 & 142 & 20 & & 1. & 417 & 77 & 45 & 0 & \begin{tabular}{l|l}
15 & 4 \\
\end{tabular} & 4.93 \\
\hline & & & 12 & 98 & & 39 & 93 & 2 & \begin{tabular}{|l|l|}
108 & 1 \\
\end{tabular} & 133 & & 17 & & & 7 & & 19 & & & 26 & 158 & & & 2 & & 5 & 43 & 20 & $\begin{array}{ll}64 \\
\end{array}$ & 4.49 \\
\hline & & & & 83 & & 37 & & & 71 & 12 & & & & & & & 9 & & & 6 & & & & 1 & & & & & & 39 \\
\hline 124 & & 59 & 5 & .59 & 27 & 2.74 & .43 & 71 & 105 & 127 & & 13 & 19 & 54 & 7 & 96 & 19 & 122 & 301 & 24 & 149 & 19 & & 3 & 343 & 72 & 33 & 19 & 13 & 5.9 \\
\hline 125 & & & 75 & 33 & & 61 & 45 & & \begin{tabular}{|l|l}
99 \\
\end{tabular} & 120 & & & & & 4 & 4 & 17 & 122 & & 25 & 157 & 18 & & 2 & 389 & 70 & 19 & 50 & \begin{tabular}{l|l}
14 & 6 \\
\end{tabular} & 6.85 \\
\hline & & & 83 & .28 & & 2.43 & .98 & & \begin{tabular}{|l|l}
94 \\
\end{tabular} & 112 & & 5.39 & & & 6 & 4 & 17 & 14 & & 23 & 139 & & & 24 & 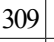 & 62 & 462 & & 38 & 8.82 \\
\hline 127 & & 91 & 1.46 & 47 & 0.29 & 2.6 & 14.2 & 0.66 & \begin{tabular}{|l|l|}
98 \\
\end{tabular} & 114 & & 5.75 & 17 & 51 & 3 & 6 & 17 & 120 & 4 & 24 & 146 & 18 & & 2 & 394 & 62 & 45 & 6 & \begin{tabular}{l|l}
15 & 7 \\
\end{tabular} & 32 \\
\hline 128 & & & 32 & 53 & & 2.5 & 15.53 & & \begin{tabular}{|l|}
97 \\
\end{tabular} & 111 & & 5.67 & 0 & & 7 & 11 & 18 & 117 & 2 & 24 & 144 & 18 & & 3 & 320 & 66 & 46 & 30 & \begin{tabular}{l|l}
14 & 7 \\
\end{tabular} & 7.52 \\
\hline & & & .55 & 49 & & & .84 & & \begin{tabular}{|l|l}
93 \\
\end{tabular} & 104 & & & & & 1 & 1 & 16 & 113 & & 23 & 148 & & & & & 6 & 35 & 8 & $14 \quad 9$ & 9.76 \\
\hline 130 & & 02 & & 5.6 & & 3.2 & 9.88 & 0.72 & \begin{tabular}{|l|l}
113 & 1 \\
\end{tabular} & 122 & & 6.07 & 18 & 56 & 61 & 97 & 20 & 127 & 3 & 26 & 154 & 19 & & 2 & 317 & 73 & 26 & 4 & 14 & 4.6 \\
\hline P131 & 77 & 2.67 & .08 & 2.66 & & 2.66 & 14.93 & 69 & 104 & 127 & 0 & 5.69 & 16 & 3 & 9 & 12 & 19 & 140 & 345 & 25 & 146 & 20 & & 1 & 331 & 64 & 32 & 39 & \begin{tabular}{|l|l}
14 & 5 \\
\end{tabular} & 5.77 \\
\hline & & & & & & 2. & 19 & 0.68 & \begin{tabular}{|l|l|}
107 \\
\end{tabular} & 12 & & 5.82 & & & & & 18 & 126 & & 25 & 146 & & & & 30 & 64 & 51 & 22 & \begin{tabular}{|l|l}
14 & 5 \\
\end{tabular} & 5.35 \\
\hline & & 16 & .34 & 35 & & 2.6 & & & 111 & 127 & & 5.93 & 16 & 5 & 4 & & 20 & & & 25 & 53 & 19 & & 3 & & 77 & 37 & 1 & \begin{tabular}{l|l}
14 & 5 \\
\end{tabular} & 46 \\
\hline P134 & & 2.6 & .04 & .5 & & 2.85 & 11.62 & 0.68 & \begin{tabular}{|l|l}
99 & 1 \\
\end{tabular} & 131 & & 5.84 & 17 & 5 & 42 & 111 & 18 & 128 & 371 & 26 & 157 & 19 & & 0 & 342 & 74 & 35 & 21 & \begin{tabular}{l|l}
14 & 4 \\
\end{tabular} & 4.16 \\
\hline & & & 38 & 39 & & 2.5 & & 0. & \begin{tabular}{|l|l|}
148 & 1 \\
\end{tabular} & 170 & & 7.05 & 2 & & 48 & 26 & 25 & 4 & & 30 & 138 & 22 & & 2 & 437 & 83 & 50 & 2 & \begin{tabular}{|l|l}
16 & 1 \\
\end{tabular} & 1.56 \\
\hline & & 41 & 27 & .06 & & 2.52 & 11.71 & 0.87 & \begin{tabular}{|l|l}
149 \\
\end{tabular} & 172 & & 95 & 30 & 82 & 51 & 125 & 23 & 125 & 322 & 29 & 144 & 22 & & 1 & 421 & 82 & 83 & 23 & \begin{tabular}{|l|l}
15 & 1 \\
\end{tabular} & 1.56 \\
\hline EMP137 & 0.95 & 3.35 & 7.84 & 47 & 28 & 2.54 & & 86 & \begin{tabular}{|l|l}
143 & 1 \\
\end{tabular} & 168 & & 7.08 & 28 & 86 & 50 & 122 & 24 & 126 & 321 & 29 & 143 & 22 & & 3 & 433 & 86 & 72 & 20 & \begin{tabular}{|l|l}
16 & 1 \\
\end{tabular} & 1.7 \\
\hline & & 3 & & & 0 & 2.41 & & & 132 & 156 & & & 2 & 7 & 3 & 11 & 2 & 118 & 343 & 28 & 142 & 21 & c & 3 & 395 & 76 & 73 & 24 & \begin{tabular}{|l|l}
16 & 2 \\
\end{tabular} & 2.92 \\
\hline MP139 & & 2.1 & 5.71 & .58 & 28 & 2.63 & 12.21 & 0.73 & 101 & 132 & & 6.02 & 16 & 57 & 36 & 91 & 17 & 121 & & 25 & 146 & 19 & 1 & 1 & 332 & 74 & 26 & 26 & \begin{tabular}{|l|l}
14 & 5 \\
\end{tabular} & 5.37 \\
\hline
\end{tabular}

Figura 3. Concentraciones elementales determinadas para los 29 individuos de Empúries. Los elementos mayores, menores y la PAF se expresan en masa \%; los elementos traza en microgramos por gramos (elaboración propia). 
donde $\mathrm{Sd}$ es el símplex d-dimensional y $\mathrm{g}(\mathrm{x})$ es la media geométrica de todos los $\mathrm{d}+1$ componentes de $\mathrm{x}$. El desarrollo del tratamiento estadístico se ha realizado con el programa estadístico $\mathrm{R}$ ( $\mathrm{R}$ Core Team, 2017).

El primer paso ha consistido en medir el grado de variabilidad existente en la muestra. En este caso, la variación total se puede considerar alta $(\mathrm{vt}=1,93) \mathrm{su}-$ giriendo que nos encontramos ante una muestra poligenética (Buxeda y Kilikoglou, 2003). La uniformidad de la variabilidad composicional se mide de acuerdo con la información de la entropía $\left(\mathrm{H}_{2}\right)$, también conocida como índice de Shannon (Shannon, 1948), en el cual los valores $\tau$.i se encuentran en orden decreciente (Buxeda y Madrid, 2016). Si se observa el gráfico de uniformidad de la variabilidad composicional (Fig. 4), se puede apreciar cómo la mayor parte de la variabilidad se encuentra relacionada con las concentraciones relativas del $\mathrm{Cr}, \mathrm{Na}_{2} \mathrm{O}, \mathrm{CaO}$ y $\mathrm{Ni}$. La información de la entropía se encuentra por encima del $80 \%$ del valor total asequible $\left(\mathrm{H}_{2} \%=85,78 \%\right)$, indicando que la variabilidad química estaría relacionada con un alto número de componentes.

Si centramos nuestra atención en la matriz de diagramas de dispersión de estos cuatro elementos $(\mathrm{Cr}$, $\mathrm{Na}_{2} \mathrm{O}, \mathrm{CaO}$ y Ni) (Fig. 5), esta permite observar al-

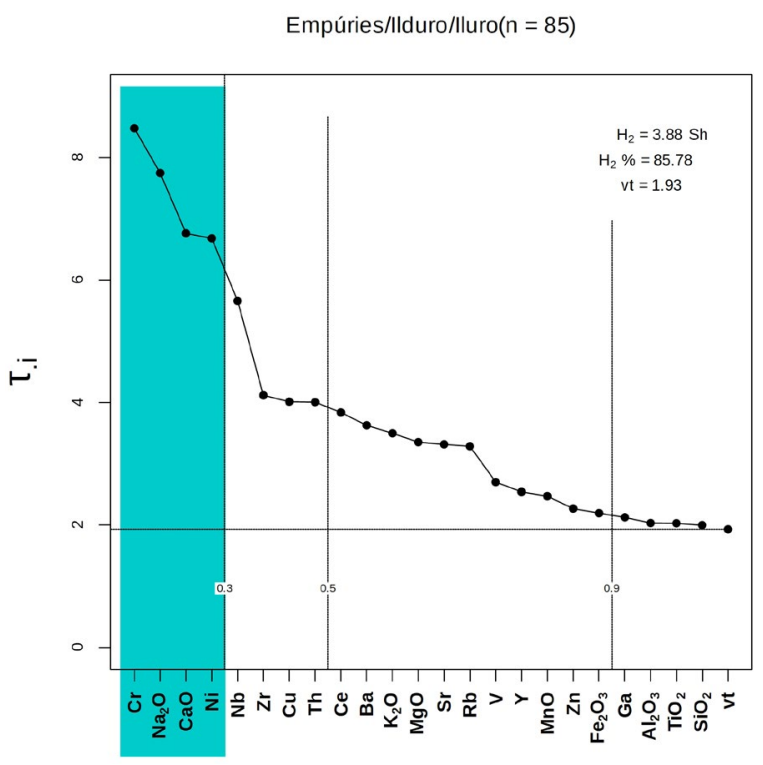

Figura 4. Gráfico de uniformidad de los 29 individuos de Empúries más los 56 de Ilduro e Iluro analizados previamente. $\mathrm{H}_{2}=$ entropía de la información, $\mathrm{H}_{2} \%$ = porcentaje de la entropía de la información sobre el máximo valor posible. $\mathrm{vt}=$ variación total. $\tau$.i suma de las variancias de las concentraciones a partir de la transformación alr con el componente i como denominador (elaboración propia). gunas de las diferencias composicionales más importantes a la hora de discriminar entre producciones. De entrada, una distribución de las muestras en dos grupos es evidente para los cuatro casos, visible, también, a través de gráficos de densidad de los componentes que se encuentran en las diagonales. Para el diagrama formado por el $\mathrm{Na}_{2} \mathrm{O} / \mathrm{g}(\mathrm{x})$ y el $\mathrm{Crg}(\mathrm{x})$, así como para el formado por el $\mathrm{Na}_{2} \mathrm{O} / \mathrm{g}(\mathrm{x})$ y el Ni/g(x) puede intuirse un tercer grupo de individuos que se encuentran en medio de las dos aglomeraciones más extremas. Hay que destacar también, que se observa una clara correlación negativa entre el $\mathrm{Na}_{2} \mathrm{O} / \mathrm{g}(\mathrm{x})$ y el Ni/g(x) y el $\mathrm{Cr} / \mathrm{g}(\mathrm{x})$, lo que significa que para todos los individuos de la muestra analizada a medida que los valores del $\mathrm{Na}_{2} \mathrm{O} / \mathrm{g}(\mathrm{x})$ aumentan, los de $\mathrm{Ni} / \mathrm{g}(\mathrm{x})$ y $\mathrm{Cr} / \mathrm{g}(\mathrm{x})$ disminuyen. Por otro lado, se observa una clara correlación positiva entre los componentes $\mathrm{Ni} / \mathrm{g}(\mathrm{x})$ y $\mathrm{Cr} / \mathrm{g}(\mathrm{x})$, indicando que a medida que los valores de uno se incrementan, también son más elevados los del otro.

Con la finalidad de observar si la posible estructura sugerida en esta matriz está formada por las mismas muestras, centramos nuestra atención en los diagramas bivariantes de la figura 6 , que son los que ilustran mejor la posible presencia de hasta tres grupos distintos. Efectivamente, en ambos casos, se forma un grupo en la parte inferior, a la derecha en el $\mathrm{Na}_{2} \mathrm{O} / \mathrm{g}(\mathrm{x})-\mathrm{Cr} / \mathrm{g}(\mathrm{x})$ (Fig. $6 \mathrm{~A}$ ) y a la izquierda en el Ni/g(x) - Cr/g(x) (Fig. $6 \mathrm{~B})$, compuesto por los mismos individuos y en el que se encuentran integrados los individuos EMP118 y EMP120, ambos clasificados arqueológicamente como Campaniense A tardía. Ciertamente, todos los individuos de este grupo pertenecen arqueométricamente al grupo de la Campaniense A (Madrid y Sinner, 2019). Por su parte, aproximadamente en el centro de ambos gráficos, se encuentran todos los individuos que durante su análisis arqueológico se clasificaron como imitaciones de Campaniense A (de EMP111 a EMP116) y dos individuos que se clasificaron como Campaniense A tardía (EMP117 y EMP119). Finalmente, el grupo, que en ambos gráficos se encuentra en la parte superior, engloba el resto de los individuos de la muestra mezclados con los que en el estudio realizado en los yacimientos de Ilduro e Iluro se identificaron con el centro productor de Cales, sin que, a este nivel de análisis, se puedan observar diferencias entre ellos.

Continuando con el tratamiento estadístico de los datos químicos, presentamos el dendrograma (Fig. 7) que muestra, en primer lugar, una estructura compleja que, en parte, se corresponde con la observada anteriormente: así vemos como la Campaniense A y las imitaciones de Campaniense A (EMP 2) se sitúan cada una en uno de los extremos del gráfico, corroborando que las discrepancias observadas durante su 
LA VAJILla de BARNIZ NEGRo EN EMPÚRIES y LA LAYETANIA. ORIGEN Y TÉCNICA DE PRODUCCIÓN A PARTIR DE SU CARACTERIZACIÓN ARQUEOMÉTRICA

Empúries/llduro/lluro
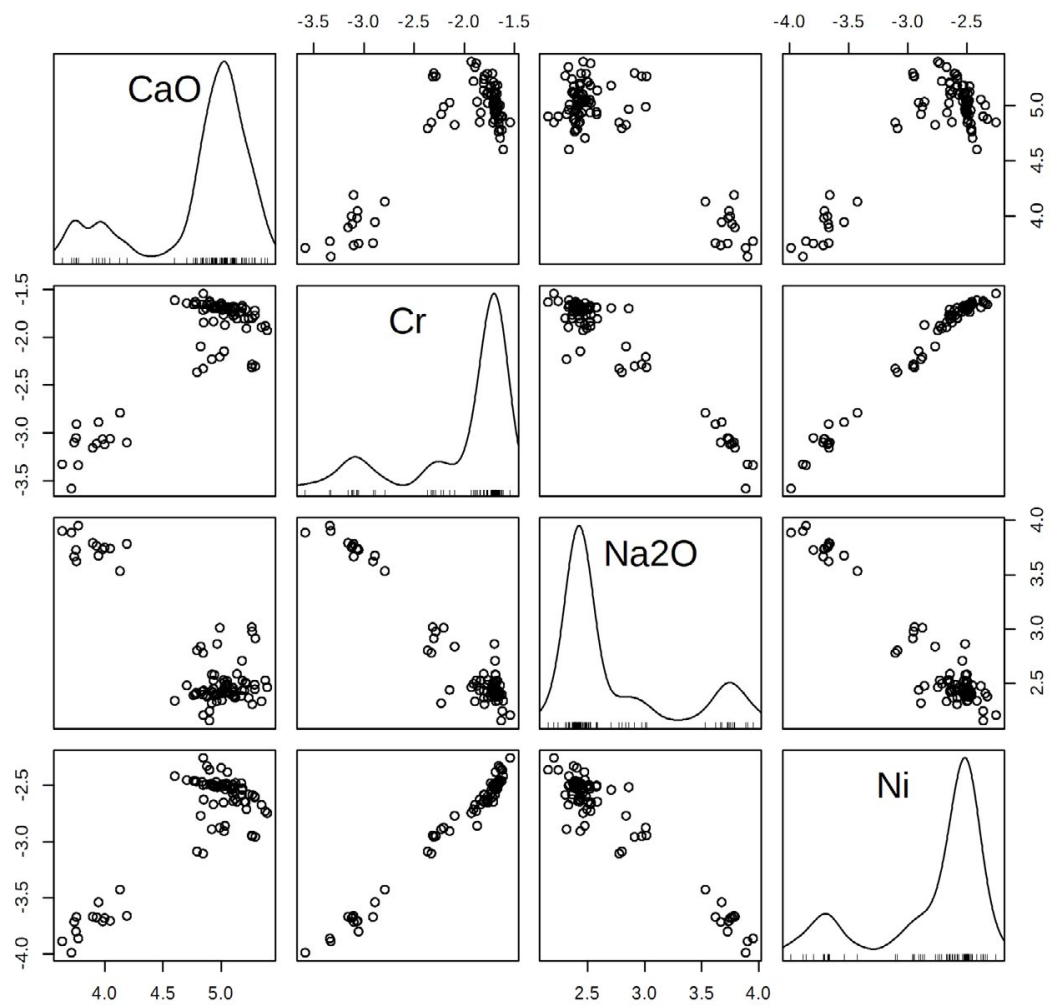

Figura 5. Matriz de diagramas bivariantes de los componentes $\mathrm{Cr}, \mathrm{Na}_{2} \mathrm{O}, \mathrm{CaO}$ y $\mathrm{Ni}$ en transformación clr. En la diagonal, se observan las estimaciones de densidad por kernels (elaboración propia).
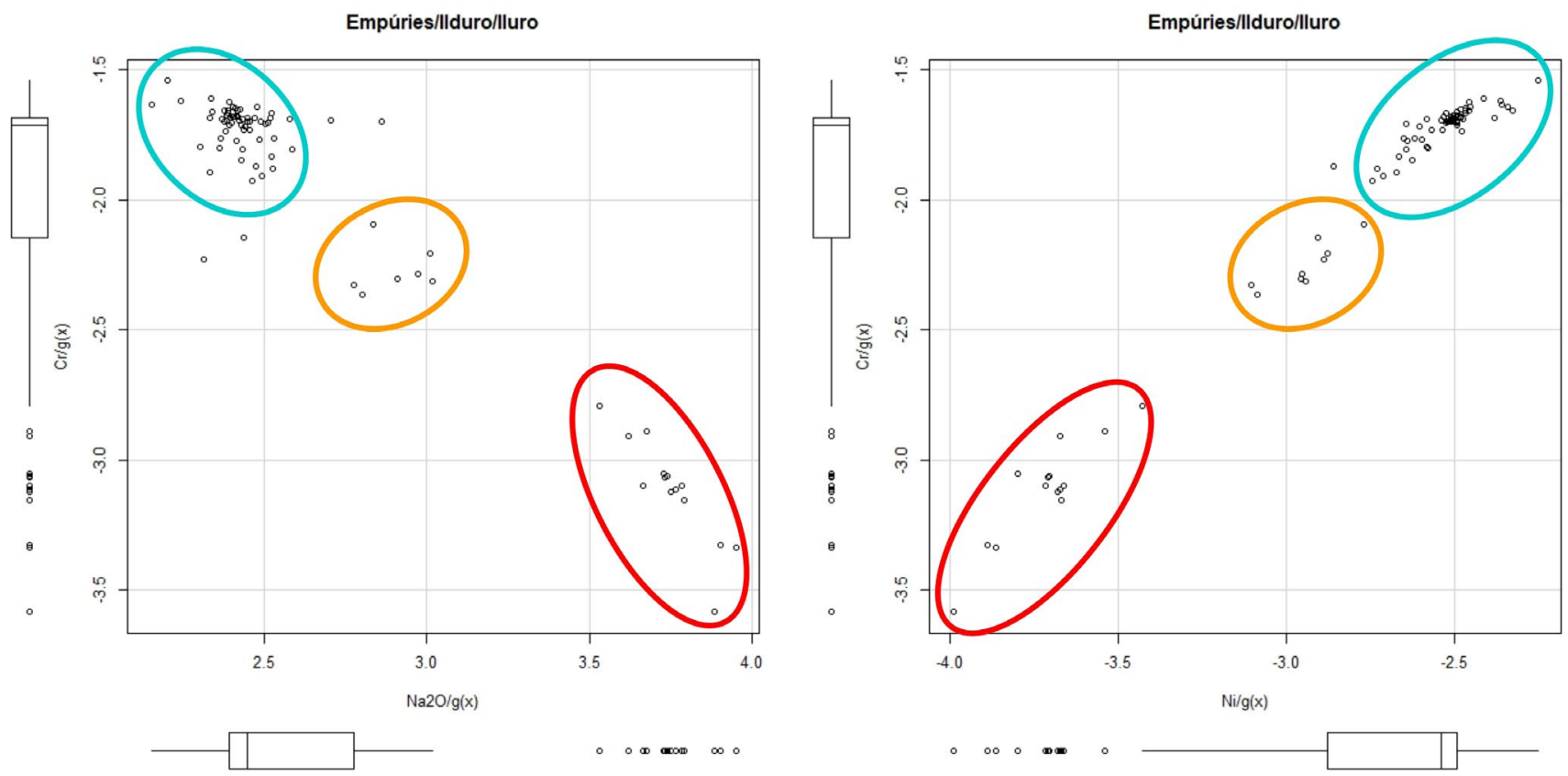

Figura 6. Gráficos bivariantes. Izquierda: $\ln \left(\mathrm{Na}_{2} \mathrm{O} / \mathrm{g}(\mathrm{x})\right)$ en abscisas vs. $\ln (\mathrm{Cr} / \mathrm{g}(\mathrm{x}))$ en ordenadas. Derecha: $\ln (\mathrm{Ni} / \mathrm{g}(\mathrm{x}))$ en abscisas vs. $\ln (\mathrm{Cr} / \mathrm{g}(\mathrm{x}))$ en ordenadas (elaboración propia).

Archivo Español de Arqueología, 2021, 94, e01 | ISSN-L: 0066-6742 | eISSN: 1988-3110 | https://doi.org/10.3989/aespa.094.021.01

9 


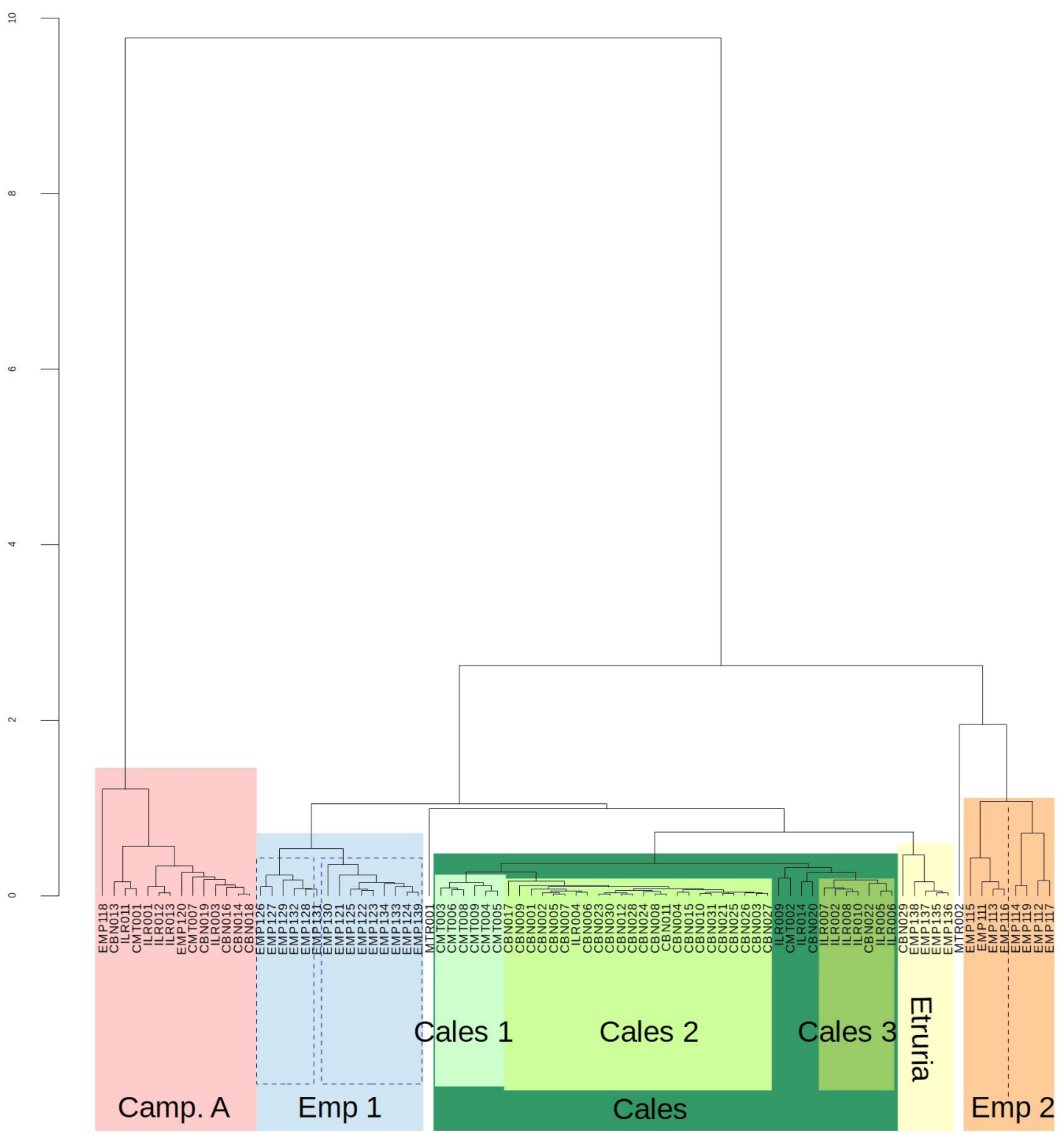

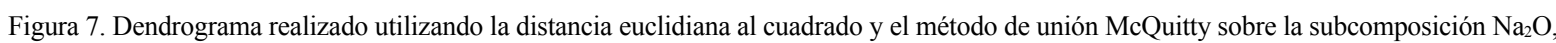
$\mathrm{MgO}, \mathrm{Al}_{2} \mathrm{O}_{3}, \mathrm{SiO}_{2}, \mathrm{~K}_{2} \mathrm{O}, \mathrm{CaO}, \mathrm{TiO}_{2}, \mathrm{~V}, \mathrm{Cr}, \mathrm{MnO}, \mathrm{Fe}_{2} \mathrm{O}_{3}$ (como Fe total), Ni, Cu, Zn, Ga, Rb, Sr, Y, Zr, Nb, Ba, Ce y Th (elaboración propia).

estudio arqueológico son el resultado de diferencias composicionales significativas. Entre estos dos grupos se observa una estructura subdividida en diversos subgrupos: en el centro se sitúan los individuos relacionados con Cales, que, a su vez, se subdividen en tres grupos Cales-1, Cales-2 y Cales-3. La asociación de estos individuos con el centro productor de Cales se realizó a partir del contraste de nuestros resultados con los obtenidos por otros autores que han trabajado sobre este centro. A partir de los primeros estudios realizados (Magetti et al., 1981, pp. 199-200; Picon,
1988, p. 222) se identificaron dos pastas diferentes: una llamada "antigua", que presentaba unos contenidos en $\mathrm{CaO}=9,54 \pm 1,39$, y otra llamada "reciente" con la que, además de cerámica de barniz negro, también se fabricó cerámica terra sigillata y que presenta un contenido ya superior en óxido de calcio $(\mathrm{CaO}=$ $13,09 \pm 1,35$ ). Posteriormente, Morel y Picon (1994) en un estudio analítico sobre la cerámica de barniz negro fabricada en diferentes zonas de la península itálica proporcionaron para Cales un único grupo de referencia, los valores del cual se encontrarían entre 
la pasta "antigua" y la pasta "reciente" definidas anteriormente. Comparando nuestros resultados, pudimos relacionar nuestro Cales-1 con el grupo de pasta "antigua"; nuestro grupo Cales-2 con el grupo que Morel y Picon definieron en el año 1994, y que ocupa una posición intermedia entre la pasta "antigua" y la "reciente"; y, finalmente, nuestro grupo Cales-3 con la pasta "reciente", la que presenta un mayor contenido de óxido de calcio, producto de haber utilizado una mayor cantidad de calcita para la preparación de esta última pasta (Madrid y Sinner, 2019, p. 3169). Cabe además destacar que el contraste de los individuos con su contexto arqueológico nos permitió observar que aquellos individuos englobados en el grupo Cales-1 y relacionados con la pasta "antigua" se correspondían cronológicamente con los contextos más antiguos, aquellos contextos de Ilduro datados en el último cuarto del siglo II a. C.; el segundo grupo, Cales-2, a su vez se correspondía con aquellos contextos de $\mathrm{Il}$ duro datados alrededor del 80/70 a. C. (momento ya final del asentamiento); mientras que los individuos englobados en el grupo Cales-3, el relacionado con la pasta "reciente", son ya de los primeros momentos de la nueva ciudad de Iluro, asentamiento que se funda cuando Ilduro se abandona (García, 2017; Madrid y Sinner, 2019, pp. 3168-3169). Siguiendo con los resultados químicos, es realmente destacable el hecho de que ninguno de los individuos de Empúries se integre dentro de estos subgrupos, especialmente teniendo en cuenta que arqueológicamente todos han sido clasificados como calenos. Los individuos de Empúries han quedado englobados en dos grupos, a izquierda y derecha de Cales. En el grupo EMP 1 se encuentran integrados los materiales clasificados como calenos (antiguo, medio y/o tardío) y uno, EMP139, como etrusco. A su vez, este grupo parece subdividirse en dos: a la izquierda, los individuos clasificados como Cales tardío, mientras que a la derecha se mezclan muestras clasificadas como Cales antiguo, medio y tardío. Finalmente, los individuos clasificados como etruscos forman un grupo junto con la única muestra etrusca identificada en Ilduro/Iluro.

Con el fin de investigar la consistencia de la estructura sugerida en este dendrograma y a la vez observar la relación de los individuos con los mismos componentes retenidos para el análisis anterior, se presentan en la Figura 8, los biplots de covarianza y forma resultantes de la descomposición en valores singulares realizada a partir de la transformación en logaritmos de razones centrados (clr) (Aitchison y Greenacre, 2002; Greenacre, 2010; van de Boogaart y Tolosana-Delgado, 2013). El resultado de los dos principales componentes visibles en los biplots de covariancia y forma explican el 90,22\% de la variancia, debido en gran parte a la gran diferencia composicional entre la Campaniense A y el resto de la muestra. En el centro de la imagen en el gráfico de covariancia y a la derecha en el de forma se sitúan el resto de los indi-
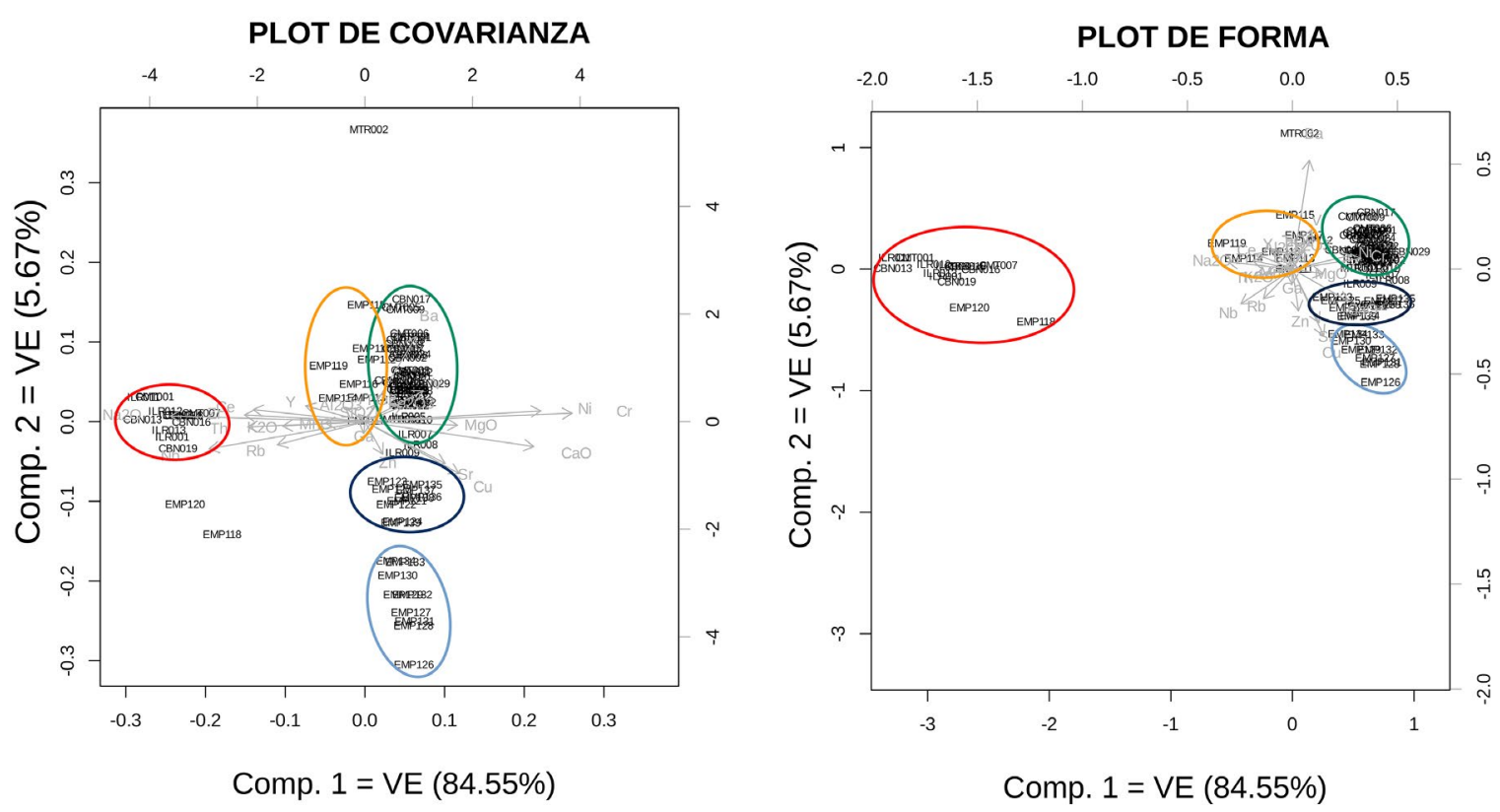

Figura 8. Gráficos bivariantes de la descomposición en valores singulares sobre la subcomposición mencionada con transformación clr con doble centrado. Izquierda: Gráfico de covariancia. Derecha: Gráfico de forma. VE: variancia explicada (elaboración propia). 


\begin{tabular}{|c|c|c|c|c|c|c|c|c|c|c|c|c|c|c|c|c|c|}
\hline & \multicolumn{2}{|c|}{$\begin{array}{c}\text { Campaniense } \\
\mathbf{A}(\mathrm{n}=14)\end{array}$} & \multicolumn{2}{|c|}{$\begin{array}{c}\text { Imitaciones } \\
\text { Camp. A } \\
(\mathbf{n}=8)\end{array}$} & \multicolumn{2}{|c|}{$\begin{array}{c}\text { Etrusco/ } \\
\text { Lacial 1 } \\
(\mathrm{n}=12)\end{array}$} & \multicolumn{2}{|c|}{$\begin{array}{c}\text { Etrusco/ } \\
\text { Lacial } 2(n=6)\end{array}$} & \multicolumn{2}{|c|}{$\begin{array}{c}\text { Volterra } \\
(n=4)\end{array}$} & \multirow[t]{2}{*}{$\begin{array}{c}\text { Etrusca } \\
\text { (CBN029) }\end{array}$} & \multicolumn{2}{|c|}{$\begin{array}{c}\text { Cales } 1 \\
(\mathrm{n}=6)\end{array}$} & \multicolumn{2}{|c|}{$\begin{array}{l}\text { Cales 2 } \\
(\mathrm{n}=23)\end{array}$} & \multicolumn{2}{|c|}{$\begin{array}{c}\text { Cales } 3 \\
(n=7)\end{array}$} \\
\hline & $\mathrm{m}$ & $\mathrm{sd}$ & $\mathrm{m}$ & $\mathrm{sd}$ & $\mathrm{m}$ & $\mathrm{sd}$ & $\mathrm{m}$ & $\mathrm{sd}$ & $\mathrm{m}$ & $\mathrm{sd}$ & & $\mathrm{m}$ & $\mathrm{sd}$ & $\mathrm{m}$ & $\mathrm{sd}$ & $\mathrm{m}$ & $\mathrm{sd}$ \\
\hline $\mathrm{Na}_{2} \mathrm{O}(\%)$ & 3.43 & 0.29 & 1.31 & 0.29 & 0.92 & 0.06 & 0.89 & 0.09 & 0.89 & 0.12 & 0.78 & 0.87 & 0.03 & 0.88 & 0.06 & 0.89 & 0.04 \\
\hline MgO (\%) & 1.59 & 0.12 & 2 & 0.11 & 2.86 & 0.22 & 2.83 & 0.2 & 3.4 & 0.06 & 3.43 & 2.94 & 0.13 & 2.83 & 0.1 & 2.93 & 0.13 \\
\hline $\mathrm{Al}_{2} \mathrm{O}_{3}(\%)$ & 19.23 & 28 & 17.55 & 1.1 & 16.24 & 0.39 & 15.27 & 0.37 & 18 & \begin{tabular}{|l|}
0.53 \\
\end{tabular} & 18.59 & 17.65 & 0.57 & 16.51 & 0.42 & 15.8 & 0.33 \\
\hline $\mathrm{SiO}_{2}(\%)$ & 60.49 & 0.47 & 56.25 & 3.31 & 57.49 & 1.08 & 55.18 & 0.59 & 54.73 & 0.34 & 55.36 & 58.68 & 0.69 & 57.69 & .76 & 56.34 & 0.62 \\
\hline $\mathrm{K}_{2} \mathrm{O}(\%)$ & 5.02 & 0.3 & 2.31 & 0.75 & 2.94 & 0.17 & 2.7 & 0.08 & 2.51 & 0.05 & 2.3 & 2.72 & 0.1 & 2.85 & 0.06 & 2.99 & 0.13 \\
\hline $\mathrm{CaO}(\%)$ & 98 & 0.72 & 12.57 & 2.44 & 12.12 & 1.41 & 16.09 & 1.09 & 12.15 & 0.85 & 11.01 & 9.06 & 0.66 & 11.69 & 1.12 & 13.78 & 0.89 \\
\hline $\mathrm{TiO}_{2}(\%)$ & 0.72 & .01 & 0.83 & 0.06 & 0.74 & 0.02 & 0.69 & 0.02 & \begin{tabular}{|l|}
0.86 \\
\end{tabular} & 0.02 & 91 & 0.82 & 0.02 & 0.77 & 0.02 & 0.73 & 0.02 \\
\hline V (ppm) & 86 & 6 & 114 & 17 & 112 & 6 & 105 & 4 & 144 & 7 & 155 & 130 & 6 & 125 & 10 & 128 & 11 \\
\hline $\mathrm{Cr}$ (ppm) & 36 & 8 & 82 & 8 & 134 & 7 & 122 & 7 & 168 & 6 & & 52 & 4 & 142 & 4 & 139 & 4 \\
\hline$(\%)$ & 0.14 & & & 0.01 & 0.1 & 0.01 & 0.1 & 0.01 & 0.14 & 0.01 & & 0.11 & 0.01 & 0.1 & 0.01 & 0.1 & 0.01 \\
\hline $\mathrm{Fe}_{2} \mathrm{O}_{3}(\%)$ & 5.1 & 0.23 & 6.82 & 0.53 & 6.33 & 0.19 & 5.98 & 0.1 & 7 & 0.15 & 7.15 & 6.87 & 0.15 & 6.42 & 0.17 & 6.17 & 0.18 \\
\hline $\mathrm{Ni}(\mathrm{ppm})$ & 20 & 3 & 41 & 5 & 59 & 4 & 55 & 4 & 83 & 3 & 91 & 68 & 2 & 63 & 2 & 59 & 4 \\
\hline $\mathrm{Cu}$ (ppm) & 2 & 3 & 39 & 6 & 42 & 8 & 65 & 12 & 48 & 5 & 52 & 39 & 5 & 35 & 2 & 36 & 5 \\
\hline Zn (ppm) & 8 & 7 & 94 & 8 & 104 & 8 & 117 & 6 & 124 & 3 & 107 & 84 & 5 & 84 & 3 & 81 & 3 \\
\hline Ga (ppm) & 18 & 1 & 21 & 1 & 20 & 1 & 18 & 1 & 24 & 1 & 20 & 17 & 1 & 17 & 1 & 16 & 0 \\
\hline Rb (ppm) & & 22 & 119 & 18 & 135 & 7 & 129 & 9 & 124 & 3 & 93 & 103 & 9 & 117 & 4 & 116 & 7 \\
\hline Sr (ppm) & 174 & 18 & 277 & 31 & 320 & 35 & 367 & 7 & 328 & 15 & 282 & 253 & 9 & 274 & 18 & 306 & 10 \\
\hline Y (ppm) & 41 & 1 & 35 & 4 & 27 & 1 & 26 & 1 & 29 & 1 & 30 & 28 & 1 & 26 & 1 & 26 & 1 \\
\hline $\mathrm{Zr}$ (ppm) & 360 & 23 & 191 & 21 & 160 & 6 & 154 & 4 & 143 & 3 & 148 & 165 & 4 & 156 & 3 & 153 & 3 \\
\hline Nb (ppm) & 52 & 4 & 20 & 1 & 19 & 2 & 20 & 1 & 22 & 1 & 19 & 17 & 1 & 16 & 1 & 16 & 1 \\
\hline Ba (ppm) & 346 & 31 & 693 & 110 & 393 & 42 & 358 & 36 & 424 & 18 & 570 & 601 & 41 & 534 & 39 & 506 & 28 \\
\hline Ce (ppm) & 167 & 10 & 92 & 8 & 77 & 4 & 68 & 2 & 82 & 4 & 94 & 81 & 4 & 76 & 4 & 73 & 6 \\
\hline Th (ppm) & 32 & 2 & 18 & 1 & 15 & 1 & 15 & 1 & 16 & 1 & 17 & 14 & 1 & 13 & 1 & 13 & 1 \\
\hline
\end{tabular}

Figura 9. Media (m) y desviación estándar (sd) de los cinco grupos definidos (Campaniense A, imitaciones de Campaniense A, etrusco/lacial 1, etrusco/lacial 2, Volterra) y de los grupos definidos en Ilduro/Iluro (Madrid y Sinner 2019, tabla 3; elaboración propia).

viduos agrupados de acuerdo con lo que hemos visto en el dendrograma, reforzando la estructura propuesta anteriormente para la muestra estudiada. Así, vemos que los individuos de Cales se sitúan en la parte superior formando una nube de puntos bastante compacta, especialmente en el biplot de forma; por debajo, se encuentran los individuos de Empúries EMP 1, distribuidos en dos grupos distintos, corroborando la subdivisión observada en el dendrograma. Finalmente, a la izquierda de Cales se encuentran las imitaciones de Campaniense A. Los componentes más importantes en la discriminación de estos grupos, fácilmente observables en el biplot de covariancia, son los mismos revelados en el gráfico de uniformidad composicional (Fig. 4), $\mathrm{Cr}, \mathrm{Na}_{2} \mathrm{O}$, Ni y $\mathrm{CaO}$. A estos hay que añadir $\mathrm{Sr}, \mathrm{Zn}$ y $\mathrm{Cu}$ que ayudan en la discriminación de los dos grupos de Empúries contenidos en EMP 1, así como el Ba que ayudaría a discriminar las imitaciones de Campaniense A (Fig. 9).

Como último paso, estos resultados han sido cotejados con los datos de materiales similares que se encuentran en la base de datos del ARQUB. Esta comparación tenía un doble objetivo; por un lado, aproxi- marnos al origen de los materiales analizados, ya que a parte de aquellos que han quedado asociados a la Campaniense A itálica, el resto no se corresponde con los analizados en Ilduro e Iluro. Por otro lado, el contraste con el barniz negro de Cosa nos permitiría observar si existían patrones coincidentes para la distribución de materiales entre esta ciudad y los yacimientos del nordeste peninsular, comparación que resultó negativa en los casos de Ilduro e Iluro. La base de datos contiene barniz negro tardorrepublicano recuperado en Cosa, terra sigillata de Arezzo, Pisa, la zona del Lacio y de la Campania, en la mayoría de los casos, posterior a los materiales que nos ocupan. No obstante, en muchas ocasiones, las materias primas utilizadas para la fabricación de ambas producciones y los centros de producción en los que estas cerámicas se elaboran son coincidentes y, por tanto, son relevantes en un estudio de proveniencia como el desarrollado en este artículo. Por otro lado, también se han tenido en cuenta los materiales de referencia del taller de Rosas, de cronología más antigua (mediados del siglo IV a finales siglo III a. C.). Aun así, creemos que, si hubiera un taller local/ regional que hubiera fabricado las llamadas imitacio- 
nes de Campaniense A, podría haber utilizado materias primas similares lo que implicaría una ubicación cercana o en el territorio de Rosas, una ciudad que ya tenía tradición en la fabricación de cerámica de barniz negro (Vendrell-Saz et al., 1991).

El resultado de esta comparación se puede observar en la Figura 10. El primer grupo corresponde a la Campaniense A, incluyendo EMP118 y EMP120. El siguiente grupo con individuos de Empúries es el del taller de Rosas que incluye las imitaciones de Campaniense A, lo que confirma la existencia de un taller local en el que fuese el territorio de la ciudad de Rosas, pero también los individuos EMP117 y EMP119, clasificados como Campaniense A tardía, confirmando su carácter local/regional. Los siguientes grupos en los que se incluyen individuos de Empúries son los que hemos denominado etrusco/lacial 1 y etrusco/lacial 2 debido a sus características composicionales. El primero incluye individuos clasificados arqueológicamente como Cales antiguo, medio, tardío y etrusco, mientras que el segundo engloba las muestras clasificadas como Cales tardío. Como ya se observaba en el dendrograma de la Figura 7, estos dos grupos se diferencian claramente de los definidos para Cales, quedando incluso en este nuevo tratamiento a una distancia todavía mayor de este, reforzando sus diferencias composicionales; es decir, que no serían producciones calenas. Por otro lado, también son evidentes sus diferencias con aquellos individuos que se engloban en grupos de centros o áreas etruscas, destacando las diferencias para con los individuos de Empúries considerados etruscos a los que haremos referencia más adelante.

Nos encontramos, por tanto, con composiciones químicas intermedias que no se corresponden con la zona de Campania ni tampoco con la de Etruria (Fig. 9). Hay que recordar que Picon, uno de los investigadores que mejor conocía tanto la composición química de las producciones cerámicas itálicas, como la propia geoquímica de la península itálica, señala que los talleres de cerámicas finas de las zonas correspondientes a la Etruria meridional y al Lacio, de acuerdo con la geoquímica de esta zona, presentarían características composicionales que serían distintas de las de Etruria septentrional así como de la Campania, mostrando, por tanto, características intermedias de ambas regiones (Cuomo di Caprio y Picon, 1994, p. 181). El mismo Picon, en colaboración con Olcese (Olcese y Picon, 1998) subrayaba, además, la dificultad de distinguir entre producciones regionales - a menos que se trabaje directamente con los grupos de referencia de centros productores- para el área del sur de Etruria y el Lacio debido a las similitudes geoquímicas que se observan en esta zona de la península itálica. A pesar de ello, Morel y Picon ya en el año 1994 proporcionan un grupo de referencia para el barniz negro del Lacio (entendiendo una zona amplia que incluye el sur de Etruria) en el que encajarían nuestros grupos etrusco/ lacial 1 y etrusco/lacial 2 (Morel y Picon, 1994, p. 26, tabla 1). Las principales discrepancias se observan para los componentes $\mathrm{MnO}, \mathrm{Sr}$ y $\mathrm{Ba}$, los cuales, tal y como indican los autores, son susceptibles de sufrir procesos de contaminación (Morel y Picon, 1994, p. 29). Posteriormente, en un amplio proyecto centrado en la definición y caracterización arqueométrica de la cerámica común de la zona del Lacio -que también incluye el estudio de cerámica de barniz negro, terra sigillata y paredes finas, entre otras- (Olcese, 2003, con contribución de M. Picon), se observa que algunas de las cerámicas comunes de mesa de Roma se produjeron con arcillas similares a las utilizadas para la fabricación de cerámicas de barniz negro de ciertas áreas del Lacio, como por ejemplo para las de Capena, cosa que indicaría que se podrían haber fabricado en los mismos talleres. El estudio proporciona numerosos análisis, observándose importantes semblanzas con nuestros grupos etrusco/lacial 1 y etrusco/lacial 2, destacando especialmente los valores de las cerámicas calcáreas, es decir, mayoritariamente, las llamadas cerámicas de mesa (Olcese, 2003, pp. 161-166, tabla 7). Finalmente, en un estudio centrado también en el Lacio, más concretamente en la terra sigillata del área romana, se incluyen análisis con valores similares a nuestros grupos etrusco/lacial 1 y etrusco/lacial 2. Por un lado, cabe destacar la tabla 1 (Olcese y Picon, 2003, p. 14) donde se proporciona la concentración media y desviación estándar de más de 70 individuos de terra sigillata analizados y que presenta importantes similitudes con nuestros resultados. Por el otro lado, los valores del grupo 4 (Olcese y Picon, 2003, pp. 23-24, tabla 3) que presenta, según los autores, grandes similitudes con producciones "regionales" del área romana como la cerámica de barniz negro y las paredes finas, entre otras. Así, aunque no sea posible relacionar estos dos grupos con talleres o zonas más concretas debido tanto a la comentada similitud geoquímica de toda la zona que comprende desde el sur de Etruria hasta prácticamente el norte de la Campania, como a los todavía escasos avances en la localización de centros de producción, creemos que se pueden asociar estos dos nuevos grupos localizados en Empúries a esta amplia zona etrusco/lacial.

Es interesante remarcar que en el grupo etrusco/lacial 1 se incluyen dos individuos recuperados en Cosa, así como la muestra ILR009, de Iluro, que quedaba como un outlier en el estudio anterior. Esto significa que, aunque de manera probablemente puntual, también llegaron los productos de esta zona de 
la península itálica en la ciudad de Iluro. Este dato no es de extrañar debido a las complejas redes de redistribución secundaria que sabemos que existieron y conectaron Empúries tanto con el litoral como con el interior del NE peninsular como así lo demuestran los estudios de dispersión de la moneda de Ilduro y Undikesken (Campo, 2002; Sinner, 2017, pp. 97-110). Por otro lado, el hecho de que incluya individuos de Cosa significa que los productos del grupo 2 seguirían una/s ruta/s de distribución que incluiría Cosa y Empúries entre sus centros receptores. El último grupo que contiene individuos de Empúries lo hemos relacionado con Volterra, aunque esta asociación precisaría de análisis de individuos volterranos en nuestro laboratorio para que los resultados fueran totalmente comparables. Aun así, no hay duda de que se trata de productos etruscos de acuerdo con sus características químicas y proponemos Volterra a partir del contraste de nuestros resultados con los publicados por otros autores (Harari y Oddone, 1984; Pasquinucci et al., 1998; Gliozzo, Memmi y Foresi, 2001, 2003; Giorgetti, Gliozzo y Memmi, 2004; Gliozzo y Memmi Turbanti, 2004; Gliozzo et al., 2004; Comodi y Merletti, 2011).

Llegados a este punto, creemos que los resultados obtenidos son consistentes y mejoran considerablemente nuestro conocimiento de qué producciones de barniz negro tardorrepublicano llegaron a la península ibérica durante los dos últimos siglos a. C. y cuál fue su distribución. En el caso de Empúries, con los resultados obtenidos hasta el momento, no parece plausible pensar que Cales fue la producción mayoritaria, como sí se observó en los casos de Ilduro e Iluro. Se han diferenciado dos grupos que presentan diferencias sutiles y que parecen tener su origen en la zona del sur de Etruria/norte del Lacio. Estas producciones, hipotéticamente -solo futuros análisis podrán confirmar esta tendencia- podrían llegar por el norte (golfo de León), a través del cabotaje, de la misma manera que lo haría el barniz negro etrusco, fabricado probablemente en Volterra o alrededores. En lo que sí coinciden los tres yacimientos es en la presencia de Campaniense A, aunque en Empúries se detecta una producción que podría haberse fabricado en la zona de Rosas y que no hemos documentado ni en Ilduro, ni en Iluro posiblemente debido al carácter local de la misma.

Creemos que la correcta clasificación de estas cerámicas es de suma importancia dada su naturaleza como fósil director. La adscripción a un tipo (p. e., Cales medio o tardío) o a una zona determinada (p. e., Cales o Etrusca) puede comportar una cronología más o menos concreta que se relaciona con los contextos en los que se recupera la cerámica, así como con las estructuras y el resto de los materiales con los que esta está asociada. En el caso concreto de Empúries, la ma- yor parte de los materiales se asociaban a Cales y, a la luz de los resultados obtenidos, Cales no parece haber llegado a Empúries de forma mayoritaria. Con esto, no queremos decir que los talleres que fabricaron los productos que pertenecen a los grupos etrusco/lacial 1 y etrusco/lacial 2 difieran cronológicamente de aquellos de Cales -aunque podría darse el caso-, pero aun así, conocer el verdadero origen nos ayudará poco a poco a configurar un panorama más certero sobre qué producciones y territorios de la península itálica -con las repercusiones sociales, culturales y económicas que ello conlleva- participaron activamente de forma directa o indirecta en el comercio con Empúries y el nordeste peninsular.

Como hemos puesto de manifiesto en estudios anteriores (Madrid y Sinner, 2019), la dificultad y las diferencias que se observan entre la clasificación arqueológica y la arqueométrica (Fig. 11) se producen principalmente porque la primera se realiza en función de la apariencia visual de las cerámicas: grosor del barniz, textura, color y color y textura de la matriz. El problema es que diferenciar productos, aunque estén fabricados en distintos talleres, elaborados a partir de unas materias primas similares y que siguen un proceso de fabricación análogo, resulta muy complicado cuando no imposible a simple vista. Además, las características visuales (apariencia) de estas cerámicas son el resultado de un proceso técnico que, como veremos en detalle a continuación, comporta diferentes grados de complejidad dependiendo del producto final que se desea obtener. Cualquier variación en ese proceso resultará en productos visualmente distintos que, en realidad, podrían pertenecer a un mismo artesano o taller (Fig. 12).

\section{RESULTADOS MINERALÓGICOS Y MICROESTRUCTURALES}

Los resultados químicos muestran que los individuos analizados en este estudio se corresponden con cerámicas consideradas técnicamente como poco calcáreas $\mathrm{CaO}<5-6 \%)$ y calcáreas $(\mathrm{CaO}>5-6 \%)$. Las cerámicas poco calcáreas desarrollan menos fases mineralógicas de alta temperatura que las cerámicas calcáreas y una microestructura más densa con una rápida formación de una fase vítrea (Heimann y Maggetti, 2014). Por otro lado, el proceso de cocción en atmósfera reductora, que es el caso del barniz negro, acelera la descomposición de las fases minerales primarias y la formación del estadio de sinterización/vitrificación, aproximadamente a unos $50{ }^{\circ} \mathrm{C}$ menos que si la cocción se produce en atmósfera oxidante (Maggetti et al., 1981, pp. 3-4).

Como paso previo a la cocción, a la cerámica de barniz negro se le aplica una barbotina de partícula 


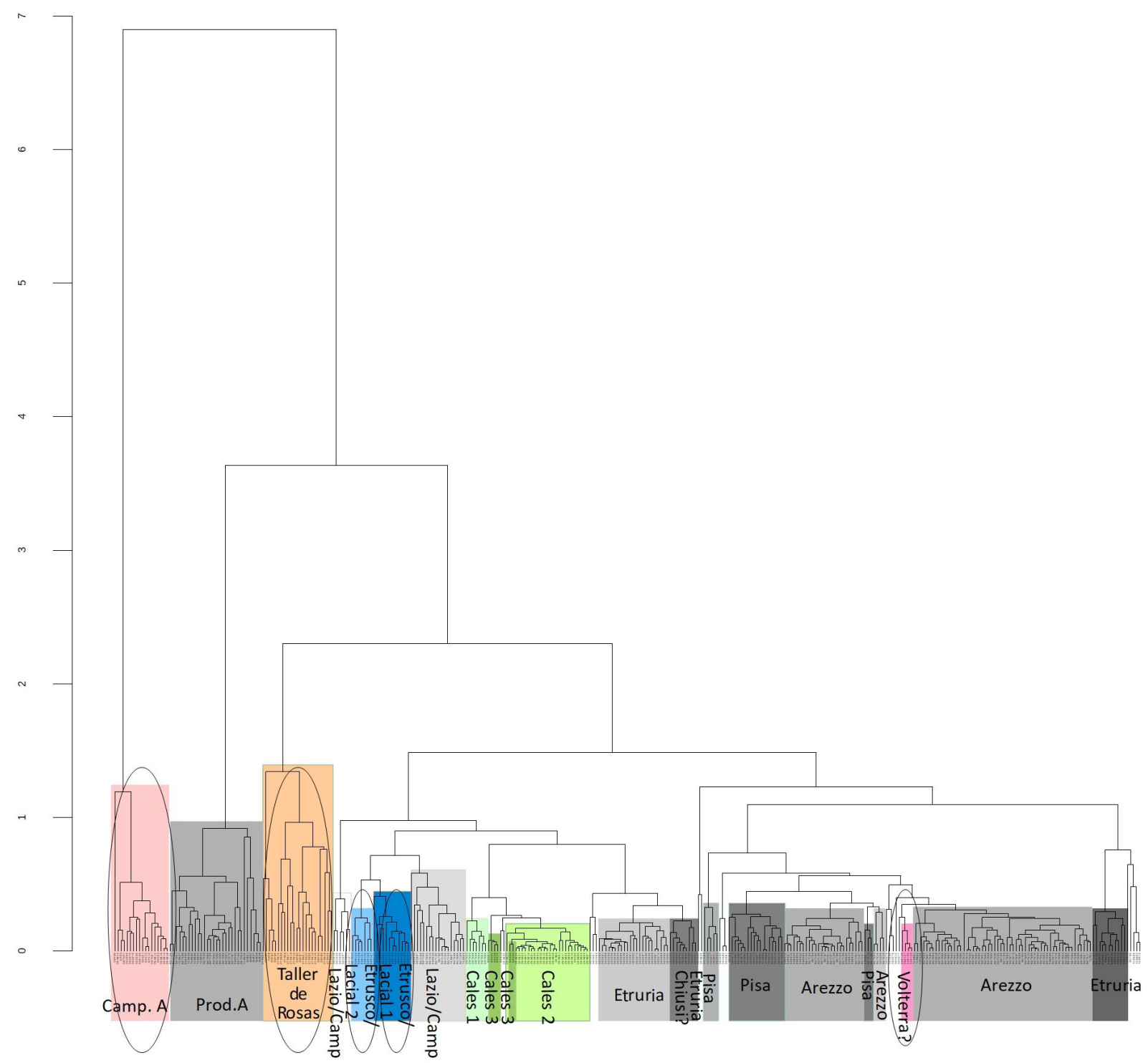

Figura 10. Dendrograma realizado utilizando la distancia euclidiana al cuadrado y el algoritmo aglomerativo del centroide sobre la subcomposición transformada por clr $\mathrm{Na}_{2} \mathrm{O}, \mathrm{MgO}, \mathrm{Al}_{2} \mathrm{O}_{3}, \mathrm{SiO}_{2}, \mathrm{~K}_{2} \mathrm{O}, \mathrm{CaO}, \mathrm{TiO}_{2}, \mathrm{~V}, \mathrm{Cr}, \mathrm{MnO}, \mathrm{Fe}_{2} \mathrm{O}_{3}$ (como Fe total), $\mathrm{Ni}, \mathrm{Cu}, \mathrm{Zn}, \mathrm{Ga}, \mathrm{Rb}, \mathrm{Sr}, \mathrm{Y}$, $\mathrm{Zr}, \mathrm{Nb}, \mathrm{Ba}, \mathrm{Ce}$ y $\mathrm{Th}$ (elaboración propia).

\begin{tabular}{|l|c|c|c|c|c|c|}
\hline $\begin{array}{l}\text { Clasificación arqueológica vs } \\
\text { post-estratificación arqueométrica }\end{array}$ & Camp. A & $\begin{array}{c}\text { Imitaciones } \\
\text { Camp. A }\end{array}$ & Etrusco/Lacial 1 & Etrusco/Lacial 2 & Volterra & Total \\
\hline Imitaciones Camp. A (6) & & 6 & & & & 6 \\
\hline Camp. A tardía & $(4)$ & 2 & 2 & & & \\
\hline Cales antiguo & $(3)$ & & 3 & & & 3 \\
\hline Cales medio & $(2)$ & & 2 & & & 2 \\
\hline Cales tardío & & & 3 & 6 & & 9 \\
\hline Etrusca & $(5)$ & & 1 & & 4 & 5 \\
\hline Total (29) & 2 & 8 & 9 & 6 & 4 & 29 \\
\hline
\end{tabular}

Figura 11. Estratificación de la muestra basada en criterios arqueológicos (ordenadas) vs post-estratificación basada en la caracterización arqueométrica (abcisas) (Buxeda y Madrid, 2016; elaboración propia). 

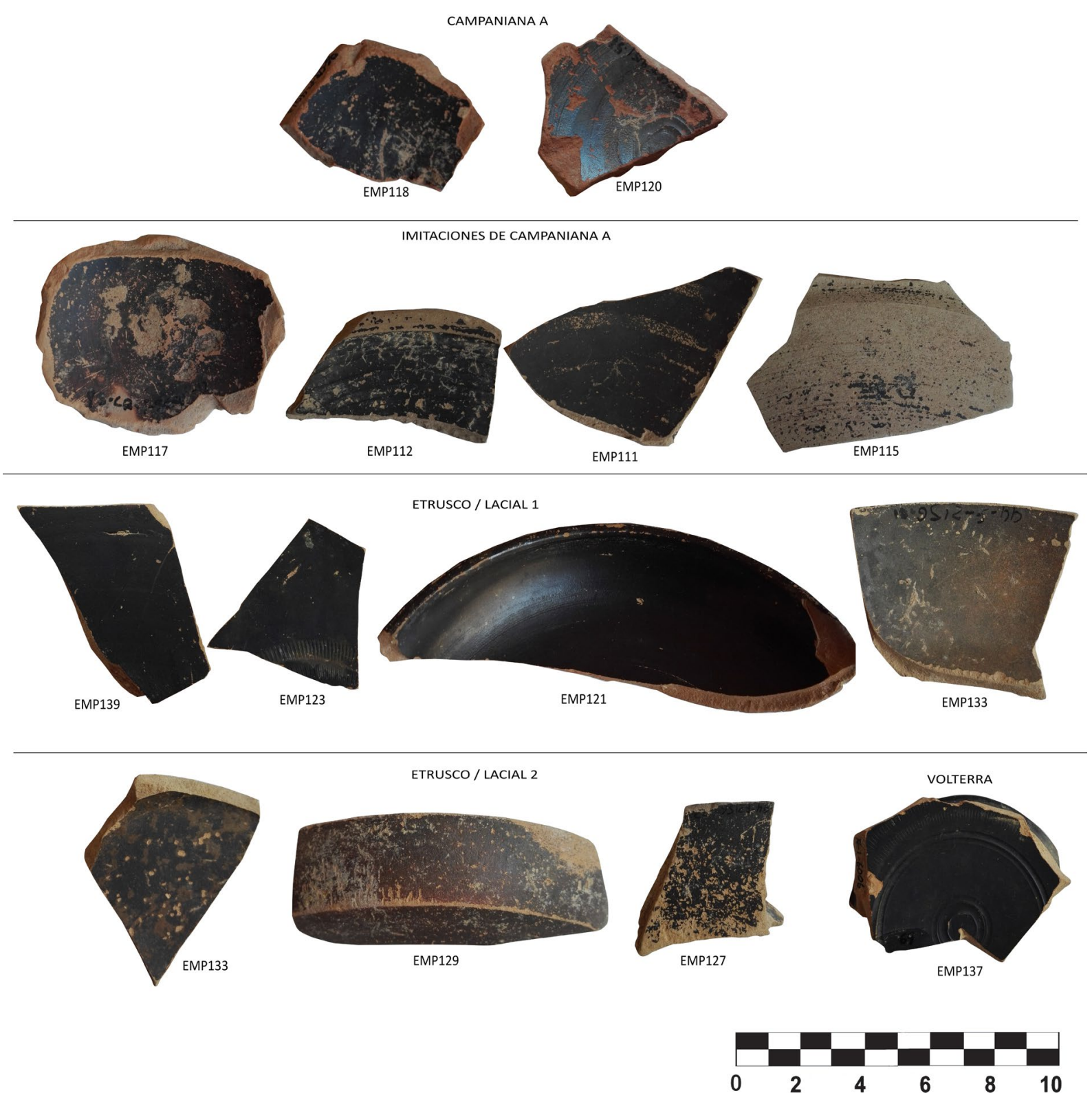

Figura 12. Individuos representativos de los grupos químicamente significativos definidos en este estudio (elaboración propia).

fina elaborada a partir de una arcilla illítica no calcárea sobre el cuerpo cerámico, con el fin de obtener un barniz impermeable y brillante. El paso final, como ya explicó Maggetti et al. (1981, pp. 3-4) y se ha confirmado por estudios recientes (Chaviara y Aloupi, 2016, pp. 10-11), comporta un proceso de cocción con una primera fase en una atmósfera oxidante hasta $800{ }^{\circ} \mathrm{C}$, una fase reductora a una temperatura máxima entre 900-950 ${ }^{\circ} \mathrm{C}-\mathrm{a}$ mayor temperatura los óxidos de hierro se descomponen con lo que la fina capa de barniz que está formada por abundante óxidos de hierro co- rre el peligro de descomponerse- y un proceso de enfriamiento en atmósfera oxidante. Una de las mejores explicaciones de este proceso ha sido publicada por Gliozzo et al. (2004, pp. 227-228).

En el caso que nos ocupa, y como se puede observar en el diagrama de fases llamado triángulo cerámico $\mathrm{CaO}\left(+\mathrm{Fe}_{2} \mathrm{O}_{3}+\mathrm{MgO}\right)-\mathrm{SiO}_{2}+\mathrm{Al}_{2} \mathrm{O}_{3}$ (Fig. 13), la cerámica Campaniense A se sitúa en el límite del triángulo de equilibrio termodinámico anortita-mulita-cuarzo y cuarzo-anortita-wollastonita debido a su carácter poco calcáreo, mientras que los 
Triángulo cerámico

(\% en peso)

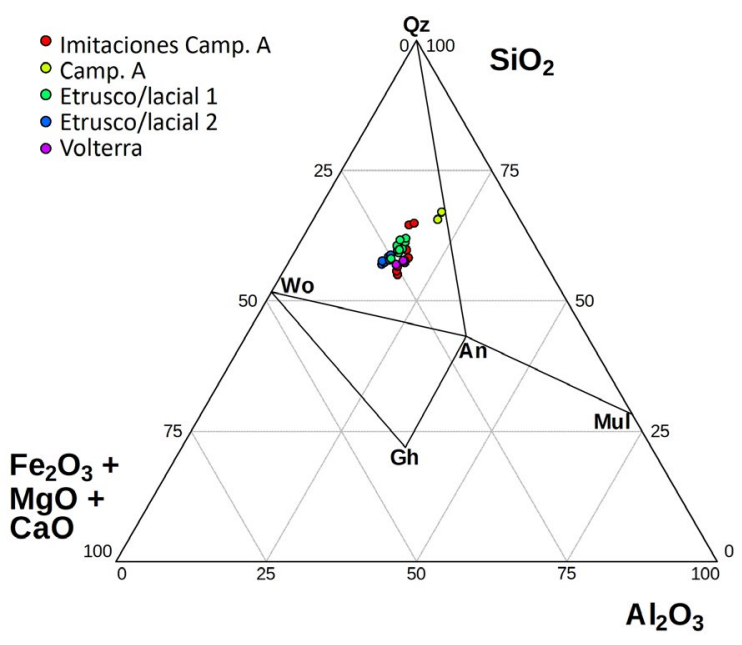

Figura 13. Diagrama de fase del triángulo cerámico $\mathrm{CaO}\left(+\mathrm{Fe}_{2} \mathrm{O}_{3}+\mathrm{MgO}\right)-\mathrm{SiO}_{2}+\mathrm{Al}_{2} \mathrm{O}_{3}$ con la situación de los individuos analizados. An: anortita $\left(\mathrm{Ca}\left[\mathrm{Al}_{2} \mathrm{Si}_{2} \mathrm{O}_{8}\right]\right)$, Gh: gehlenita $\left(\mathrm{Ca}_{2} \mathrm{Al}(\mathrm{Si}, \mathrm{Al})_{2} \mathrm{O}_{7}\right)$; Mul: mullita $\left(\mathrm{Al}_{6}\left[\mathrm{Si}_{2} \mathrm{O}_{13}\right]\right) ; \mathrm{Qz}$ : cuarzo $\left(\mathrm{SiO}_{2}\right)$; Wo: wollastonita $\left(\mathrm{CaSiO}_{3}\right)$ (abreviaturas según Whitney y Evans, 2010; elaboración propia).

individuos etruscos, los etruscos-laciales y aquellos de imitación de Campaniense A se sitúan en el triángulo cuarzo-anortita-wollastonita, característico de las cerámicas calcáreas. A continuación, se exponen los puntos más destacados de los resultados correspondientes a la caracterización mineralógica y microestructural (Figs. 14 y 15), así como las características del barniz (Figs. 15 y 16), de acuerdo con los grupos definidos a partir del tratamiento estadístico de los resultados químicos.

\subsection{Imitaciones de Campaniense A}

El estudio de los difractogramas de los ocho individuos clasificados como imitaciones de Campaniense A (EMP111 a 117 y 119) nos ha permitido la identificación de cuatro fábricas (F1 a F4) de acuerdo con las diferentes fases cristalinas observadas (Figs. 14 y 15$)^{2}$. Cabe destacar que las principales diferencias entre fábricas se producen por la paulatina des-

2 Entendemos fábrica como el producto final después de la cocción. En este sentido, una pasta puede resultar en más de una fábrica distinta (Buxeda y Madrid, 2016, p. 36). composición de los filosilicatos de illita-muscovita, la disminución de la calcita, así como el desarrollo de los piroxenos y la gehlenita, fases de cocción características de las cerámicas calcáreas. En este caso, también es interesante la presencia de analcima en las F3 y F4, una zeolita sódica que, cuando no es primaria -como en este caso-, aparece típicamente en la alteración de cerámicas calcáreas con sobrecocciones poco severas (Buxeda, 1999; Schwedt et al., 2006). Típicamente, este proceso de alteración comporta además de la cristalización de la analcima, incorporando sodio alóctono, una lixiviación de alcalinos, especialmente potasio, y a veces de rubidio (Zacharias et al., 2007). En este caso, la afectación de estos tres componentes por este proceso de alteración se puede observar en sus valores más altos de $\mathrm{Na}_{2} \mathrm{O}$ y más bajos en $\mathrm{K}_{2} \mathrm{O}$ y $\mathrm{Rb}$ en estos individuos respecto a aquellos del mismo grupo que no están alterados. Todo ello nos permite estimar una TCE en el rango $800 / 850-950^{\circ} \mathrm{C}$ para la $\mathrm{F} 1$; en el rango 900 $950{ }^{\circ} \mathrm{C}$, probablemente cerca ya de $\operatorname{los} 950{ }^{\circ} \mathrm{C}$ debido a la total descomposición de la illita-muscovita para la F2; y por encima de los $950 / 1000{ }^{\circ} \mathrm{C}$ para las dos últimas fábricas, F3 y F4. Las observaciones de las matrices por MEB corroboran las estimaciones realizada por DRX, observándose para la F1 un estadio de sinterización de la matriz de vitrificación inicial (IV) (Fig. $17 \mathrm{~A})$ y de vitrificación continuada (V) para las otras tres fábricas (Fig. $17 \mathrm{C} \mathrm{y} \mathrm{E).} \mathrm{A} \mathrm{su} \mathrm{vez,} \mathrm{el} \mathrm{grosor}$ del barniz va disminuyendo a medida que aumenta la temperatura (Fig. 18, Fig. 17 B, D y F). En general, se trata de un barniz con numerosas burbujas en la zona de interacción con la matriz cosa que provoca una baja adherencia a esta, por lo que se escamaría fácilmente. Lo que justifica el aspecto de la mayoría de los individuos correspondientes a este grupo, los cuales presentan un barniz que se desprende con facilidad (Fig. 12).

\subsection{Campaniense $\mathrm{A}$}

En el caso de los dos individuos correspondientes a esta producción (EMP118 y EMP120) (Figs. 14 y 15 ), sus difractogramas se corresponden con la fábrica F2 de Campaniense. A identificada en Ilduro e Iluro (Madrid y Sinner, 2019, fig. 12 b). Así, para ambos se estima una TCE baja, en torno a los $800{ }^{\circ} \mathrm{C}$, que coincide con la observación por MEB que indica un estadio de vitrificación IV-V de la matriz y un barniz de unos $15 \mu \mathrm{m}$ y una buena adherencia a la matriz. Se observan también numerosas inclusiones que no se han llegado a fundir, probablemente porque la baja temperatura no ha permitido una completa vitrificación (Fig. 17). 


\begin{tabular}{|c|c|c|c|c|c|}
\hline $\begin{array}{l}\text { RESULTADOS } \\
\text { MINERALÓGICOS Y } \\
\text { MICROESTRUCTURALES }\end{array}$ & Fábricas & Color y apariencia & $\begin{array}{c}\text { Microestructura } \\
\text { de la matriz }\end{array}$ & Barniz & $\begin{array}{c}\text { Temperatura } \\
\text { de cocción } \\
\text { equivalente (TCE) }\end{array}$ \\
\hline Campaniense A & $\begin{array}{l}\text { F2 (EMP118, } \\
\text { EMP120) }\end{array}$ & $\begin{array}{l}\text { Afs, Anl, Hem, Ilt (1 pico } \\
10 \AA), P 1, Q z\end{array}$ & $\mathrm{IV} / \mathrm{V}$ & No vitrificado & $\sim 800^{\circ} \mathrm{C}$ \\
\hline \multirow{4}{*}{ Imitaciones Campaniense A } & $\begin{array}{l}\text { F1 (EMP114, } 117 \\
\text { y 119) }\end{array}$ & $\begin{array}{l}\text { Afs, Cal, Gh, Hem, Ilt, Pl, } \\
\text { Px, Qz }\end{array}$ & IV & No vitrificado & $800 / 850^{\circ} \mathrm{C}-950^{\circ} \mathrm{C}$ \\
\hline & F2 (EMP112) & Afs, Cal, Gh, Hem, Pl, Px, Qz & V & Vitrificado & $900{ }^{\circ} \mathrm{C}-950^{\circ} \mathrm{C}$ \\
\hline & $\begin{array}{l}\text { F3 (EMP111, } 113 \text { y } \\
\text { 116) }\end{array}$ & $\begin{array}{l}\text { Afs, Anl, Cal, Gh, Hem, Pl, } \\
\text { Px, Qz }\end{array}$ & V & Vitrificado & $>950 / 1000{ }^{\circ} \mathrm{C}$ \\
\hline & F4 (EMP115) & Afs, Anl, Gh, Hem, Pl, Px, Qz & V & No se conserva & $>950 / 1000^{\circ} \mathrm{C}$ \\
\hline \multirow{4}{*}{ Etrusco/Lacial 1} & F1 (EMP130 y 139) & $\begin{array}{l}\text { Afs, Cal, Gh, Hem, Ilt, Pl, } \\
\text { Px, Qz }\end{array}$ & $\mathrm{IV} / \mathrm{V}$ & Vitrificado & $800^{\circ} \mathrm{C}-850^{\circ} \mathrm{C}$ \\
\hline & $\begin{array}{l}\text { F2 (EMP121, } 124 \\
\text { y 125) }\end{array}$ & $\begin{array}{l}\text { Afs, Cal, Gh, Hem, Ilt (1 } \\
\text { pico), Pl, Px, Qz }\end{array}$ & V & Vitrificado & $900^{\circ} \mathrm{C}-950^{\circ} \mathrm{C}$ \\
\hline & F3 (EMP123) & $\begin{array}{l}\text { Afs, Cal, Hem, Ilt (1 pico), Pl, } \\
\text { Px, Qz }\end{array}$ & $\mathrm{V}$ & Vitrificado & $900^{\circ} \mathrm{C}-950^{\circ} \mathrm{C}$ \\
\hline & $\begin{array}{l}\text { F4 (EMP122, } 133 \\
\text { y 134) }\end{array}$ & Afs, Cal, Gh, Hem, Pl, Px, Qz & VT & Vitrificado & $>950 / 1000{ }^{\circ} \mathrm{C}$ \\
\hline \multirow{3}{*}{ Etrusco/Lacial 2} & F1 (EMP129) & Afs, Cal, Gh, Hem, Ilt, Pl, Qz & IV/V & No vitrificado & $800^{\circ} \mathrm{C}-850^{\circ} \mathrm{C}$ \\
\hline & F2 (EMP126 y 127) & $\begin{array}{l}\text { Afs, Cal, Gh, Hem, Ilt, Pl, } \\
\text { Px, Qz }\end{array}$ & V & Vitrificado & $\sim 850^{\circ} \mathrm{C}$ \\
\hline & $\begin{array}{l}\text { F3 (EMP128, } 131 \\
\text { y 132) }\end{array}$ & Afs, Cal, Gh, Hem, Pl, Px, Qz & $\mathrm{V}$ & Vitrificado & $900^{\circ} \mathrm{C}-950{ }^{\circ} \mathrm{C}$ \\
\hline Volterra & (EMP135 a 138) & Afs, Cal, Hem?, Pl, Px, Qz & $\mathrm{IV} / \mathrm{V}$ & Vitrificado & $900^{\circ} \mathrm{C}-950^{\circ} \mathrm{C}$ \\
\hline
\end{tabular}

Figura 14. Resultados mineralógicos de DRX y observaciones microestructurales por MEB. Afs: feldespato alcalino, Anl: analcima, Cal: calcita, Gh: gehlenita, Hem: hematita, Ilt: illita-moscovita, Pl: plagioclasa, Px: piroxeno, Qz: cuarzo (Abreviaturas según Whitney y Evans 2010). IV: vitrificación inicial, V: vitrificación continuada, TV: vitrificación total (elaboración propia).

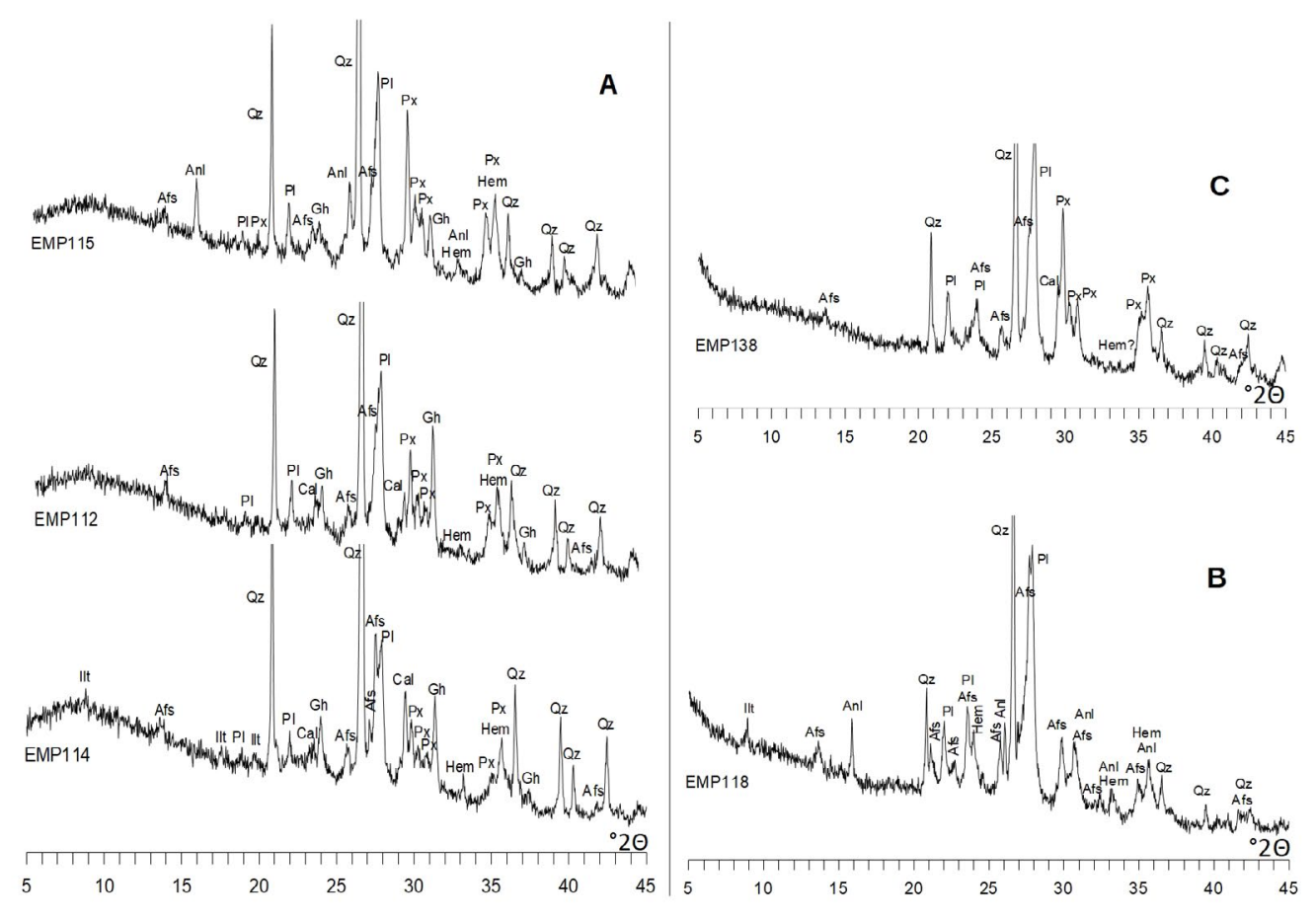

Figura 15. Difractogramas representativos de los grupos identificados en este estudio. A: Imitaciones de Campaniense A, B: Campaniense A, C: Volterra. Afs: feldespato alcalino, Anl: analcima, Cal: calcita, Gh: gehlenita, Hem: hematites Ilt: illita-moscovita, Pl: plagioclasa, Px: piroxeno, Qz: cuarzo (abreviaturas según Whitney y Evans, 2010; elaboración propia). 


\subsection{Etrusco/lacial 1}

Los difractogramas de los nueve individuos correspondientes a este grupo (EMP121 a 125, 130, 133, 134 y 139) nos han permitido la identificación de cuatro fábricas (F1 a F4) (Figs. 14 y 16). En este caso, la descomposición de illita-muscovita se produce de manera muy progresiva, estando presentes en todas las fábricas excepto en la F4. Por otro lado, se observa un aumento progresivo de los piroxenos y la presencia de gehlenita en todas las fábricas excepto en la F3. El estudio mineralógico nos permite estimar una TCE para la $\mathrm{F} 1$ en el rango de $800-850^{\circ} \mathrm{C}$; en el rango de $900-950^{\circ} \mathrm{C}$, que es el adecuado para este tipo de producciones, para la $\mathrm{F} 2$ y $\mathrm{F} 3, \mathrm{y}>950 / 1000{ }^{\circ} \mathrm{C}$ para la F4. Las observaciones por MEB permiten corroborar la TCE propuesta por DRX y observar un estadio de vitrificación IV-V para la matriz de la F1 (Fig. 17 G); de vitrificación V para la matriz de la F2 y F3 (Fig. 17 I) y de vitrificación total (VT) para la fábrica F4 (Fig. 17 K). El barniz se muestra, en gene- ral, homogéneo, con numerosas pequeñas inclusiones brillantes, correspondientes a óxidos de hierro, que van desapareciendo a medida que aumenta la temperatura y con una buena adherencia a la matriz (Fig. $17 \mathrm{H} \mathrm{y} \mathrm{J}$ y Fig. 18). La excepción es la fábrica $\mathrm{F} 4$, que presenta algunas zonas con un barniz muy grueso, con numerosas burbujas debido a la alta temperatura (Fig. 17 L). Estas características proporcionan un barniz impermeable, negro, mate, denso, en definitiva, de buena calidad incluso para la F4. En este caso, la gran cantidad de burbujas que se observan en algunas partes del barniz proporcionan un aspecto menos homogéneo, negro, pero con tonalidades más claras (Fig. 12).

\subsection{Etrusco/lacial 2}

El estudio de los difractogramas de los seis individuos de este grupo (EMP126 a 129, 131 y 132) nos ha permitido identificar tres fábricas, de F1 a F3 (Figs. 14 y 16). Como en los casos anteriores, cabe destacar la
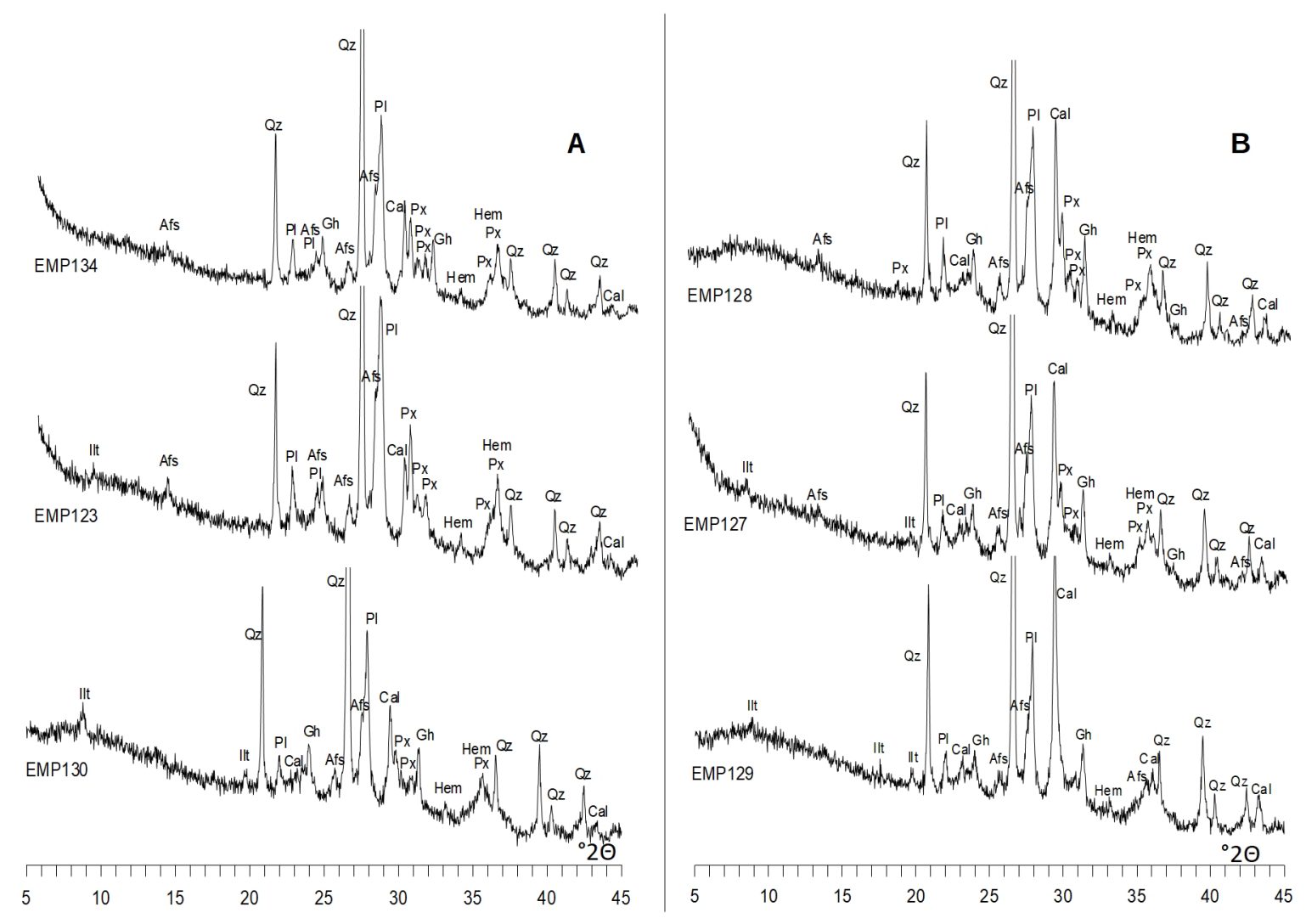

Figura 16. Difractogramas representativos de los grupos identificados en este estudio. A: Etrusco-laciales 1, B: Etrusco-laciales 2, Afs: feldespato alcalino, Cal: calcita, Gh: gehlenita, Hem: hematites Ilt: illita-moscovita, Pl: plagioclasa, Px: piroxeno, Qz: cuarzo (abreviaturas según Whitney y Evans, 2010; elaboración propia). 
progresiva descomposición de los filosilicatos de illita-muscovita, que ya no se observan en la F3, así como la disminución de la calcita. De la misma manera, se observa el desarrollo de piroxenos y, en cierto grado, de la gehlenita. Estas observaciones permiten estimar una TCE en el rango de 800-850 ${ }^{\circ} \mathrm{C}$ para la $\mathrm{F} 1$, en torno a los $850{ }^{\circ} \mathrm{C}$ para la $\mathrm{F} 2 \mathrm{y}$ en el rango de $900-950{ }^{\circ} \mathrm{C}$ para la $\mathrm{F} 3$. Las observaciones por $\mathrm{MEB}$ de las matrices de los individuos de este grupo muestran una apariencia similar a las observadas para el grupo etrusco/lacial 1. No obstante, el barniz difiere mostrando aquí una calidad más baja; aunque el grosor es similar, su aplicación es desigual con zonas donde se observan distintos grosores, una mayor porosidad en general y la presencia de inclusiones más abundante (Fig. $17 \mathrm{M} \mathrm{y}$ $\mathrm{N}$ y Fig. 18). En el caso de la fábrica F3, como también hemos visto en el caso del grupo etrusco/lacial 1 , presenta un grosor aproximado de $30 \mu \mathrm{m}$ con una gran cantidad de burbujas provocadas, probablemente, por una temperatura en el límite de la TCE por su lado superior $\left(900-950{ }^{\circ} \mathrm{C}\right)$. Todo ello junto con una baja adherencia a la matriz, proporciona un barniz que se desprende con facilidad, provocando un aspecto de baja calidad (Fig. 12).

\subsection{Etrusca, posible Volterra}

A diferencia de lo que hemos visto hasta el momento, los cuatro individuos correspondientes a la zona etrusca (EMP135 a 138) responden a una única fábrica, cosa que indica un dominio importante del proceso de producción y, especialmente, del proceso de cocción que no parece haberse alcanzado en las demás producciones aquí estudiadas (Figs. 14 y 15). Las fases cristalinas identificadas permiten proponer una TCE en el rango de $900-950{ }^{\circ} \mathrm{C}$, probablemente más cerca del rango alto. Su observación por $\mathrm{MEB}$, nos muestra una microestructura de la matriz en un estadio de vitrificación IV/V (Fig. 17 O), similar a la observada para el único individuo etrusco identificado en Ilduro/Iluro (Madrid y Sinner, 2019, fig. 15). La principal diferencia técnica respecto a aquel es el grosor de su barniz (Fig. 18), que, en el caso actual es de unos $40 \mu \mathrm{m}$, un grosor excepcional, por lo que conocemos hasta el presente en producciones de barniz negro. A pesar de ello, está bien vitrificado, con escasas y muy pequeñas inclusiones, correspondientes a óxido de hierro, y algunos poros alargados (Fig. 17 P). Su adherencia a la matriz es buena y el resultado es un barniz de muy buena calidad y fácilmente recono-

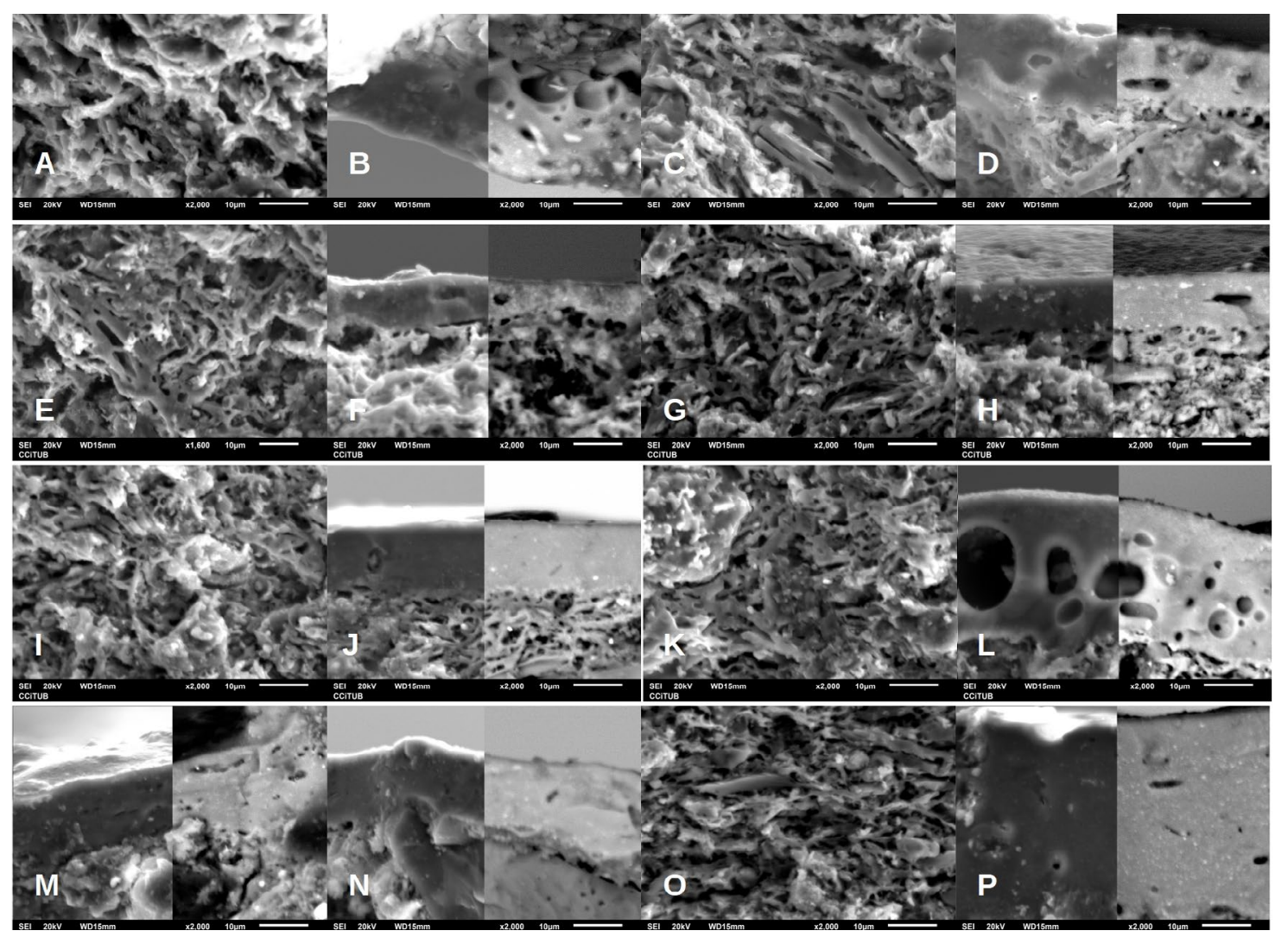

Figura 17. Microfotografías por MEB de imitaciones de Campaniense A (A a F), etrusco/lacial 1 (G a L), etrusco/lacial 2 (M y N), Volterra

(O y P). 2000X. A, C, E, G, I, K y O: matriz, imagen de electrones secundarios. B, D, F, H, J, L, M, N y P: barnices, a la izquierda: imagen de electrones retrodispersados (BSE); a la derecha: imagen de electrones secundarios (SE) (elaboración propia). 


\begin{tabular}{|c|c|c|c|c|c|c|c|c|}
\hline $\begin{array}{l}\text { CARACTERÍSTICAS } \\
\text { DEL BARNIZ }\end{array}$ & Fábricas & $\begin{array}{l}\text { Color y } \\
\text { apariencia }\end{array}$ & Estadio & Grosor & Porosidad & Inclusiones & Burbujas & $\begin{array}{l}\text { Temperatura } \\
\text { de cocción } \\
\text { equivalente } \\
\text { (TCE) }\end{array}$ \\
\hline Campaniense A & F2 (EMP118, EMP120) & $\begin{array}{l}\text { Negro mate o } \\
\text { negro plateado }\end{array}$ & $\begin{array}{l}\text { No } \\
\text { vitrificado }\end{array}$ & $15 \mu \mathrm{m}$ & $\mathrm{X}$ & XXX & & $\sim 800{ }^{\circ} \mathrm{C}$ \\
\hline \multirow{4}{*}{$\begin{array}{c}\text { Imitaciones } \\
\text { Campaniense A }\end{array}$} & F1 (EMP114, 117 y 119) & Negro mate & $\begin{array}{c}\text { No } \\
\text { vitrificado }\end{array}$ & $20 \mu \mathrm{m}$ & & $\mathrm{XX}$ & XXX & $\begin{array}{l}800 / 850^{\circ} \mathrm{C}- \\
950^{\circ} \mathrm{C}\end{array}$ \\
\hline & F2 (EMP112) & Negro mate & Vitrificado & $10 \mu \mathrm{m}$ & $\mathrm{X}$ & $\mathrm{X}$ & & $900{ }^{\circ} \mathrm{C}-950^{\circ} \mathrm{C}$ \\
\hline & F3 (EMP111, 113 y 116) & Negro mate & Vitrificado & $10 \mu \mathrm{m}$ & $\mathrm{X}$ & $\mathrm{X}$ & & $>950 / 1000{ }^{\circ} \mathrm{C}$ \\
\hline & F4 (EMP115) & No se conserva & & & & & & $>950 / 1000{ }^{\circ} \mathrm{C}$ \\
\hline \multirow{4}{*}{ Etrusco/Lacial 1} & F1 (EMP130 y 139) & $\begin{array}{l}\text { Negro mate } \\
\text { o negro mate } \\
\text { intenso }\end{array}$ & Vitrificado & $15 \mu \mathrm{m}$ & $\mathrm{XX}$ & XXX & & $800{ }^{\circ} \mathrm{C}-850^{\circ} \mathrm{C}$ \\
\hline & F2 (EMP121, 124 y 125) & $\begin{array}{l}\text { Negro mate o } \\
\text { negro brillante }\end{array}$ & Vitrificado & $10 \mu \mathrm{m}$ & $\mathrm{X}$ & $\mathrm{XX}$ & & $900{ }^{\circ} \mathrm{C}-950^{\circ} \mathrm{C}$ \\
\hline & F3 (EMP123) & $\begin{array}{l}\text { Negro mate } \\
\text { intenso }\end{array}$ & Vitrificado & $15 \mu \mathrm{m}$ & & $\mathrm{X}$ & & $900{ }^{\circ} \mathrm{C}-950{ }^{\circ} \mathrm{C}$ \\
\hline & F4 (EMP122, 133 y 134) & $\begin{array}{c}\text { Negro mate } \\
\text { o negro mate } \\
\text { intenso o negro } \\
\text { plateado }\end{array}$ & Vitrificado & $>30 \mu \mathrm{m}$ & & & $\mathrm{XXX}$ & $>950 / 1000^{\circ} \mathrm{C}$ \\
\hline \multirow{3}{*}{ Etrusco/Lacial 2} & F1 (EMP129) & $\begin{array}{c}\text { Negro mate con } \\
\text { zonas rojizas en } \\
\text { el exterior }\end{array}$ & $\begin{array}{c}\text { No } \\
\text { vitrificado }\end{array}$ & $\begin{array}{l}\text { Irregular } \\
10-15 \mu \mathrm{m}\end{array}$ & $\mathrm{XX}$ & $\mathrm{XX}$ & & $800^{\circ} \mathrm{C}-850^{\circ} \mathrm{C}$ \\
\hline & F2 (EMP126 y 127) & Negro mate & Vitrificado & $\begin{array}{l}\text { Irregular } \\
10-15 \mu \mathrm{m}\end{array}$ & & $\mathrm{X}$ & & $\sim 850^{\circ} \mathrm{C}$ \\
\hline & F3 (EMP128, 131 y 132) & $\begin{array}{l}\text { Negro plateado } \\
\text { o negro mate } \\
\text { con zonas } \\
\text { marrones en el } \\
\text { exterior }\end{array}$ & Vitrificado & $>30 \mu \mathrm{m}$ & & $\mathrm{X}$ & $\mathrm{XX}$ & $900{ }^{\circ} \mathrm{C}-950^{\circ} \mathrm{C}$ \\
\hline Volterra & (EMP135 a 138) & $\begin{array}{l}\text { Negro brillante } \\
\text { o negro mate } \\
\text { intenso }\end{array}$ & Vitrificado & $\sim 40 \mu \mathrm{m}$ & $\mathrm{X}$ & $\mathrm{X}$ & & $900{ }^{\circ} \mathrm{C}-950^{\circ} \mathrm{C}$ \\
\hline
\end{tabular}

Figura 18. Características del barniz observadas por MEB (elaboración propia).

cible macroscópicamente, resultado de un alto grado de conocimiento técnico por parte de los ceramistas etruscos (Fig. 12).

\section{CONCLUSIONES}

La caracterización arqueométrica de los 29 individuos de Empúries nos ha proporcionado un panorama distinto al esperado y que sugiere que la distribución de barniz negro tardorrepublicano en la península ibérica fue un proceso complejo en el que probablemente estuvieron involucrados más áreas productoras y talleres de los que se ha venido asumiendo tradicionalmente. Con una muestra relativamente pequeña, si la comparamos con los 56 individuos analizados en Ilduro/
Iluro, se han identificado cinco grupos diferentes que pertenecen, muy probablemente, a cinco producciones distintas. Ciertamente, se trata de un número elevado de grupos que podría incrementarse con un muestreo más amplio. Cabe recordar que Picon ya documentó en su día la presencia de cerámica calena en Empúries.

Destacan las cerámicas clasificadas arqueológicamente como imitaciones de Campaniense A. Es interesante la relación composicional que se puede establecer entre este grupo y el conocido como taller de Rosas. Como ya hemos destacado en el apartado correspondiente, la asociación se produce entre materias primas, dado que el taller finalizaría su actividad un siglo antes de que nuestras imitaciones fuesen producidas. A pesar de ello, Rosas o una zona cercana 
estaría en el origen de estas imitaciones que llegaron a Empúries hacia el tercer cuarto del siglo II a. C. A nivel técnico, se trata de una producción calcárea que se caracteriza por la presencia de individuos cocidos a diferentes temperaturas y con un barniz que varía en grosor, siempre con numerosas burbujas y una adherencia a la matriz deficiente. Todo ello permite inferir un dominio pobre de todo el proceso de fabricación y cocción que dará lugar a productos que perderán fácilmente el barniz, que es el elemento que impermeabilizaría la vajilla frente a la penetración de líquidos. Con lo cual, sería un producto con un periodo de uso limitado. Cabe destacar, finalmente, que todos los individuos clasificados arqueológicamente como imitaciones se incluyen en este grupo, pero también dos individuos clasificados como Campaniense A tardía.

Respecto a la Campaniense A propiamente dicha, los dos individuos identificados como tales presentan las características típicas de esta producción: cerámicas poco calcáreas y con un barniz que presenta una buena adherencia a la matriz. Para estos dos individuos, la clasificación arqueológica coincide con la clasificación arqueométrica.

Los resultados más sorprendentes han sido los de los grupos etrusco/laciales, 1 y 2 . Se trata de producciones que no habían sido identificadas anteriormente en el nordeste peninsular y que se daban como calenas. Así, en el grupo 1 se incluyen aquellos individuos clasificados arqueológicamente como Cales antiguo, medio y tardío, mientras que en el grupo 2 todos los individuos se habían clasificado como tardío. Se trata de dos grupos similares composicionalmente, calcáreos, siendo el 1 el que presenta las concentraciones de $\mathrm{CaO}$ más bajas. Ambos comparten el mismo proceso técnico, con individuos cocidos a diferentes temperaturas y un barniz que muestra un grosor medio, excepto para los individuos cocidos a temperatura más elevada, para los cuales el grosor es superior. A pesar de las similitudes, el barniz del grupo 1 muestra una aplicación más homogénea y una mejor adherencia a la matriz proporcionando un barniz negro y denso; en cambio el barniz del grupo 2 se desprende con facilidad debido a una deficiente adherencia a la matriz y una aplicación menos homogénea. Estas características son probablemente las causantes de la clasificación de los individuos del grupo 1 como Cales antiguo, medio, etrusco - y uno como Cales tardío- y los del grupo 2, como Cales tardío.

También se han identificado productos etruscos que se corresponden con los clasificados como tales durante su estudio arqueológico. Este grupo, que es calcáreo, es el que presenta una mayor homogeneidad a todos los niveles, composicional y técnico. En este sentido, cabe destacar que los cuatro individuos etruscos están cocidos a la misma temperatura y presentan un barniz muy grueso, con una buena adherencia a la matriz, que confiere una gran calidad a los productos finales y que resulta visible a simple vista. Hemos relacionado este grupo con Volterra a partir de datos publicados, pero podría corresponder a una zona cercana, incluso a Arezzo. De lo que no hay duda, es de su carácter etrusco, aunque difiere en cuanto a composición y barniz, de la cerámica etrusca identificada en Ilduro/Iluro.

Finalmente, respecto al contraste con Cosa, cabe destacar que el grupo etrusco/lacial 1 es el único que incluye individuos de los tres yacimientos analizados hasta el momento, es decir la colonia romana, Empúries e Iluro.

Estos resultados combinados con los obtenidos para Ilduro/Iluro dibujan, como se sugiere al principio de estas conclusiones, un panorama ciertamente más complejo de lo que esperábamos. A pesar de que no es el objetivo de este artículo analizar en profundidad las rutas que siguieron los productos de barniz negro que abastecieron el NE peninsular, nuestros resultados, así como los de otros autores (Madrid y Sinner, 2019, con bibliografía), permiten proponer que además del barniz negro procedente de la Campania, otras producciones hasta hoy desconocidas, como las etrusco/laciales aquí identificadas, también se exportaron al NE peninsular, llegando al menos a Empúries en cantidades importantes.

En trabajos anteriores llegábamos a la conclusión de que al menos se podían proponer dos circuitos principales, uno para los productos de Cales y otro para la producción Etrusca: el primero llegaría a la costa mediterránea hispana y a la Galia, y desde la costa gala llegaría hasta Baviera. El segundo sería el seguido por la cerámica etrusca, la cual a través de los Alpes abastecería a las regiones de Europa Central. No obstante, con los datos que acabamos de presentar este panorama parece complicarse, puesto que tenemos una nueva área de producción donde se ubicarían los talleres que fabricarían los productos de los grupos etrusco/lacial 1 y 2 , los cuales seguirán una ruta o rutas de las que podemos rastrear dos paradas: Cosa y Empúries (Fig. 19). Hipotéticamente, estas producciones podrían alcanzar el nordeste peninsular vía golfo de León, a través del cabotaje, de la misma manera que lo haría el barniz negro etrusco, fabricado probablemente en Volterra, Arezzo o alrededores. Una duda que solo un estudio más amplio podrá solventar, es si los productos etruscos/laciales viajaron directamente desde un puerto principal italiano (y si es así, cuál/es) hacia Massalia o algún otro puerto principal del sur Francia o del NE Peninsular -los resultados de los análisis realizados en Tarraco y Baetulo serán claves para dilucidar esta cuestión- desde donde se redistribuyen a través del cabotaje. En el caso de las ciudades layetanas, y a tenor de los datos actuales, de momento parece que los productos etrusco/laciales 
no son frecuentes. Por ello, es plausible la hipótesis de que el suministro a estos núcleos se hizo mayoritariamente $-\mathrm{o}$ al menos en parte- desde Cales, presentando un patrón de abastecimiento distinto al observado en Empúries. Con la información actual, no parece lógico considerar Emporion como el puerto principal desde el que se distribuyeron las cerámicas calenas presentes en los mercados del NE peninsular a partir del último cuarto del siglo II a. C. Quizás debamos considerar los importantes enclaves portuarios de Tarraco o Carthago Nova como los principales centros redistribuidores. En cualquier caso, debemos esperar a los resultados de los análisis de los yacimientos de Badalona y Tarragona, para poder corroborar o refutar estas hipótesis e ir completando el complejo entramado de producciones, circuitos comerciales y redes de distribución y de redistribución que debió significar el aprovisionamiento de esta vajilla.

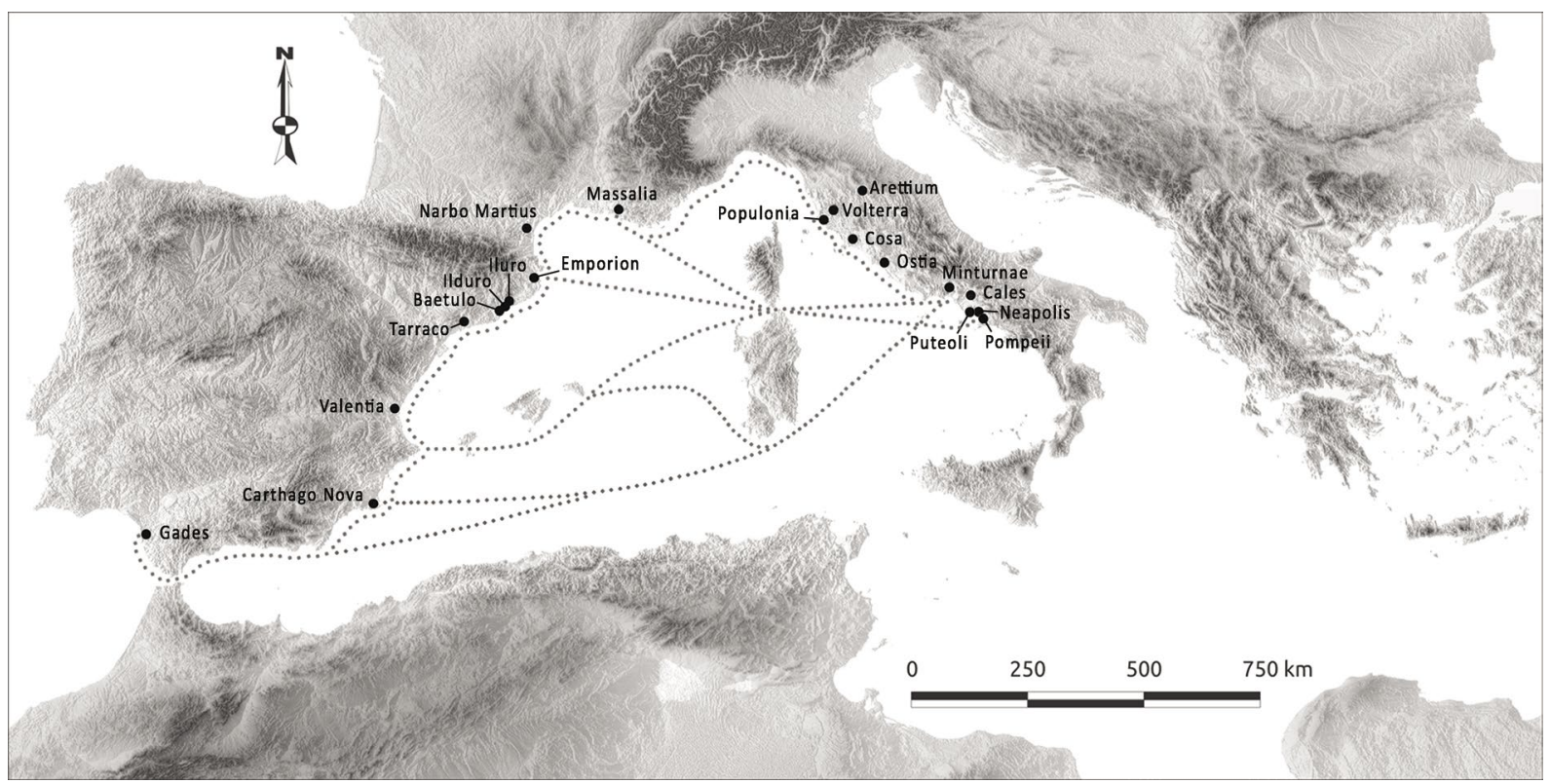

Figura 19. Posibles rutas a través de las cuales se distribuiría el barniz negro tardorrepublicano en la costa catalana (elaboración propia).

\section{BIBLIOGRAFÍA}

Aitchison, J. (1986). The statistical analysis of compositional data. Monographs on statistics and applied probability. London: Chapman and Hall.

Aitchison, J. y Greenacre, M. (2002). "Biplots of compositional data". Applied Statistics, Journal of the Royal Statistical Society: Series C, 51, pp 375-392. DOI: https://doi.org/10.1111/1467-9876.00275

Aloupi, E. (2008). "Recovery and revival of Attic Vase-Decoration techniques. Special techniques". En: Lapatin, K. (Ed.). Papers on special techniques in Athenian vases. Los Angeles: J. Paul Getty Museum, pp. 113-127.

Aquilué, X., García, J. y Guitart, J. (Eds.) (2000). La ceràmica de vernís negre dels segles II i I aC: centres productors mediterranis i comercialització a la Península Ibèrica: taula rodona. Empúries 4 y 5 de junio de 1998. Mataró: Museu de Mataró.

Aquilué, X., Castanyer, P., Santos, M. y Tremoleda, J. (2002). "El campo de silos del área central de la ciudad romana de Empúries". Romula, 1, pp. 9-38.

Aquilué, X., Castanyer, P., Santos, M. y Tremoleda, J. (2009). "Resultats de les darreres intervencions arqueològiques a la Neàpolis de la ciutat grega d'Empòrion (Empúries,
l'Escala, Alt Empordà)". Tribuna d'Arqueologia, 2009, pp. 121-147.

Aquilué, X., Santos, M., Tremoleda, J. y Castanyer, P. (2010). "Contextos d'època d'August procedents del fòrum de la ciutat romana d'Empúries". En: Revilla, V. y Roca, M. (Eds.). Contextos ceràmics i cultura material d'època augustal a l'occident romà. Actes de la reunió celebrada a la Universitat de Barcelona els dies 15 i 16 d'abril de 2007. Barcelona: Universitat de Barcelona pp. 36-91.

Asensio, D. (2010). "El comercio de ánforas itálicas en la Península Ibérica entre los siglos IV y I a.C. y la problemática en torno a las modalidades de producción y distribución". Bollettino di Archeologia on line, Volume speciale B / B8 / 3, pp. 23-41.

Buxeda i Garrigós, J. (1999). "Alteration and contamination of archaeological ceramics: the perturbation problem". Journal of Archaeological Science, 26, pp. 295-313. DOI: https://doi.org/10.1006/jasc.1998.0390

Buxeda i Garrigós, J. (2018). "Compositional Data Analysis”. En: López Varela, S. L. (Ed.). The Encyclopedia of Archaeological Sciences. Hoboken: John Wiley \& Sons, Inc., pp. 1-5.

Buxeda i Garrigós, J. y Kilikoglou, V. (2003). "Total Variation as a Measure of Variability in Chemical Data 
Sets”. En: van Zelst, L (Ed.). Patterns and Process. A Festschrift in Honor of Dr. Edward V. Sayre. Suitland: Smithsonian Center for Materials Research and Education, pp. 185-198.

Buxeda i Garrigós, J. y Madrid i Fernández, M. (2016). "Designing Rigorous Research: Integrating Science and Archaeology". En: Hunt, A. M. W. (Ed.). The Oxford Handbook of Archaeological Ceramic Analysis. Oxford: Oxford University Press, pp. 19-47.

Campo, M. (2002). "La producció d'Untikesken i Kese: Funció i circulació a la ciutat $\mathrm{i}$ al territori. Funció i producció de les seques indígenes". VI Curs d'Història monetària d'Hispània. Barcelona: MNAC, pp. 77-104.

Carreras Monfort, C., Martín Menédez, A., Pera Isern, J. y Rodrigo Requena, E. (2016). "Las ánforas de Brindisi en la Hispania Citerior. Pautas de distribución y consumo". Saguntum, 48, pp, 103-121.

DOI: https://doi.org/10.7203/sagvntvm.48.7671

Castanyer, P., Santos, M., Tremoleda, J., Puigdevall, I., Puig, A. M., Hernández, E., Cle, A. y Ferrer, A. (2016). "Intervencions arqueològiques a Empúries (L'Escala, Alt Empordà) als anys 2014 I 2015". Tretzenes Jornades d'Arqueologia de les Comarques de Girona. Banyoles: Ajuntament de Banyoles, Museu Arqueològic de Banyoles, pp. 169-198.

Chaviara, A. y Aloupi-Siotis, E. (2016). "The story of a soil that became a glaze: Chemical and microscopic fingerprints on the Attic vases". Journal of Archaeological Science: Reports, 7, pp. 510-517. DOI: https://doi.org/10.1016/j.jasrep.2015.08.016.

Comodi, P. y Merletti, M. (2011). "Ceramica a vernice nera: analisi archeometriche”. En: Bergamini, M. (Ed.). Scoppieto II. I materiali, Università degli Studi di Perugia. Firenze: Dipartimento di Scienze dell'Antichità, Sezione Scienze Storiche dell'Antichità, All'Insegna del Giglio s.a.s., pp. 121-126.

Cuomo di Caprio, N. y Picon, M. (1994). "Classification et détermination d'origine des céramiques à vernis noir et à vernis rouge d'Italie: aspects méthodologiques". En: Burragato, F., Grubessi, O. y Lazzarini, L. (Eds.). First European workshop on archaeological ceramics. Rome: Università degli Studi 'La Sapienza', pp. 163-181.

García, J. (2017). Gènesi, fundació i període republicà de la ciutat romana d'Iluro (Hispania Citerior). Laietania, 19. Mataró: Museu de Mataró.

Giorgetti, G., Gliozzo, E. y Memmi, I. (2004). “Tuscan black glosses: A mineralogical characterization by high resolution techniques". European Journal of Mineralogy, 16, pp. 493-503. DOI: https://doi.org/10.1127/0935-1221/2004/0016-0493

Gliozzo, E., Kirkman, I. W., Pantos, E. y Memmi Turbanti, I. (2004). "Black gloss pottery: production sites and technology in northern Etruria, part II: gloss Technology". Archaeometry, 46, pp. 227-246.

Gliozzo, E., Memmi, I. y Foresi, L. (2001). "Archaeometric study of ceramic production at Chiusi-Marcianella (Siena, Italy)". Proceedings of the 32nd Symposium of Archaeometry. Ciudad de México, 15-19 mayo 2000. Ciudad de México: UNAM, edición en cd-rom.
Gliozzo, E., Memmi, I. y Foresi, L. (2003). "Lo studio archeometrico delle produzioni ceramiche". En: Pucci, G. y Mascione, C. (Eds.). Manifattura ceramica Etrusco-Romana a Chiusi. Il complesso produttivo di Marcianella. Bibliotheca Archaeologica. Collana di archeologia a cura di Giuliano Volpe, 10. Bari: Edipuglia, pp. 275-314.

Gliozzo, E. y Memmi Turbanti, I. (2004). "Black gloss pottery: production sites and technology in northern Etruria, part I: provenance studies". Archaeometry, 46, pp. 201-225.

DOI: https://doi.org/10.1111/j.1475-4754.2004.00153.x

Greenacre, M. (2010). Biplots in practice. BBVA Foundation Manuals. Bilbao: Fundación BBVA.

Harari M. y Oddone, M. (1984). "Le groupe de Clusium: analyse des argyles. Ancient Greek and related pottery". En: Brijder, H. A. G. (Ed.). Proceedings of the International Vase Symposium in Amsterdam. Amsterdam, 12-15 Abril 1984. Amsterdam: Allard Pierson Series 5, pp. 16-20.

Heimann, R. B. y Maggetti, M. (2014). Ancient and Historical Ceramics. Materials, Technology, Art, and Culinary Traditions. Stuttgart: Schweizerbart Science Publishers.

Hein, A., Tsolakidou, A., Iliopoulos, I., Mommsen, H., Buxeda i Garrigós, J., Montana, G. y Kilikoglou, V. (2002). "Standardisation of elemental analytical techniques applied to provenance studies of archaeological ceramics: an inter laboratory calibration study". The Analyst, 127, pp. 542-553. DOI: https://doi.org/10.1039/b109603f

Jiménez, C. (2000). "La ceràmica de vernís negre: testimonis dels inicis de la ciutat de Baetulo". Carrer dels Arbres. Revista anuari del Museu de Badalona, 11, pp. 7-20.

Jiménez, C. (2002). Baetulo: la ceràmica de vernís negre. Una contribució a l'estudi de la romanització a la Laietània. Monografies badalonines, 17. Badalona: Museu de Badalona.

Lamboglia, N. (1952). "Per una classificazione preliminare della ceramica campana". Atti del I Congresso internazionale di Studi Liguri. Bordighera, 1950. Bordighera: Istituto di Studi Liguri, pp. 139-206.

Lamboglia, N. (1960). "Polemiche campane". Rivista di Studi Liguri, 26, pp. 292-304.

Lühl, L., Hesse, B., Mantouvalou, I., Wilke, M., Mahlkow, S., Aloupi-Siotis, E. y Kanngiesser, B. (2014). "Confocal XANES and the Attic Black Glaze: The Three-Stage Firing Process through Modern Reproduction". Analytical Chemistry, 86, pp. 6924-6930. DOI: https://doi.org/10.1021/ac500990k

Madrid i Fernández, M. y Buxeda i Garrigós, J. (2013). "Caracterización arqueométrica”. En: Roca, M., Madrid, M. y Celis, R. (Eds.). Proyecto Cosa: intervenciones arqueológicas de la Universidad de Barcelona en la ciudad romana. Barcelona: Universitat de Barcelona, pp. 111-112.

Madrid i Fernández, M. y Sinner, A. G. (2019). “Analyzing technical choices: improving the archaeological classification of Late Republican Black Gloss pottery in north-eastern Hispania consumption centers". Archaeological and Anthropological Sciences, 11, pp. 3155-3186. DOI: https:/doi.org/10.1007/s12520-018-0748-x 
Maggetti, M., Galetti, G., Schwander, H., Picon, M. y Wessicken, R. (1981). "Campanian pottery: the nature of the black coating”. Archaeometry, 23, pp. 199-207. DOI: https://doi.org/10.1111/j.1475-4754.1981.tb00306.x

Maniatis, Y., Aloupi, E. y Stalios, A. D. (1993). "New Evidence for the Nature of the Attic Black Gloss". Archaeometry, 35, pp. 23-34. DOI: https://doi.org/10.1111/j.1475-4754.1993.tb01021.x

Marín, C. y Ribera, A. (2001). "Las cerámicas de barniz negro de Cales en Hispania (y las Galias)”. En: Pedroni, L. (Ed.). Ceramica Calena A Vernice Nera. Produzione e diffusione. Città di Castello: Editorial Petruzzi, pp. 246-295

Martín-Fernández, J. A., Buxeda i Garrigós, J. y Pawlowsky-Glahn, V. (2015). "Logratio Analysis in Archeometry: Principles and Methods". En: Barceló, J. A. y Bogdanovic, L. (Ed.). Mathematics and Archaeology. Boca Raton: Science Publishers, CRC Press, pp. 178-189.

Miró, T. (1998). "La ceràmica àtica de figures roges d'Empúries. Una aproximació al seu estudi tipològic". Empúries, 51, pp. 127-138.

Morel, J. P. (1981). Céramique campanienne: les formes. 2 vols. Roma: École française de Rome.

Morel, J. P. (1990). "L'artigiano e gli artigiani”. En: Storia di Roma, vol. 2, L'impero mediterraneo, I, La repubblica imperiale. Torino: Editorial Einaudi.

Morel, J. P., Accorona, F., Laforgia, E., Schiavone Palumbo, E. y Ziviello, C. (1985). "La ceramica campana A nell'economia della Campania. La fomace di corso Umberto". Napoli Antica (Mostra). Nápoles: Editorial, pp. 372-385.

Morel, J. P. y Picon, M. (1994). "Les céramiques ètrusco-campaniennes: recherches en laboratoire”. En: Olcese, G. (Ed.). Ceramica romana e archeometria: lo stato degli studi, Atti delle giornate Internazionali di Studio. Castello di Montegufoni-Firenze, 26-27 abril 1993. Firenze: Edizioni all'Insegna del Giglio, pp. 23-46.

Nieto, X. (1988). "Cargamento principal y cargamento secundario". Cahiers d'histoire, XXXIII, 3-4, Navires et comerces de la Mediterranee antique. Hommage à Jean Rougé, pp. 379-395.

Nieto, X. (1997). "Le commerce de cabotaje et de redistribution". En: Pomey, P. (Ed.). La Navigation dans l'Antiquité. Aix-en-Provence: Édisud, pp. 146-159.

Nolla, J. M., Palahí, L. y Vivo, J. (2010). De l'oppidum a la ciuitas: la romanització inicial de la Indigècia. Girona: Institut de Recerca Històrica de la Universitat de Girona.

Olcese, G. (2003). Ceramiche comuni a Roma e in area romana: produzione, circolazione e tecnología (tarda età repubblicana - prima età imperiale). Documenti di archeologia, 28. Mantova: Editrice SAP, Società Archeologica s.r.1.

Olcese, G. (2012). Immensa Aequora 2, Atlante dei siti di produzione ceramica (Toscana, Lazio, Campania e Sicilia) con le tabelle dei principali relitti del Mediterraneo occidentale IV secolo a.C. - I secolo d.C. Roma: Ed. Quasar.

Olcese, G. (2013). Immensa Aequora 3 - Workshop. Ricerche archeologiche, archeometriche e informatiche per la ricostruzione dell'economia e dei commerci nel bacino occidentale del Mediterraneo (metà IV sec. a.C. - I sec. d.C.). Roma: Ed. Quasar.
Olcese, G. y Picon, M. (1998). "Ceramiche a vernice nera in Italia e analisi di laboratorio: fondamenti teorici e problemi aperti". Indagini archeometriche relative alla ceramica a vernice nera: nuovi dati sulla provenienza e sulla diffusione, Atti del seminario Internazione di Studio. Milano 22-23 noviembre 1996. Como: Edizioni New Press, pp. 31-37.

Olcese, G. y Picon, M. (2003). “Terra Sigillata Italica a Roma e in area romana: produziones, circolazione, e analisi di laboratorio". Rei Cretariae Romanae Favtorvm Acta, 38, pp. 11-26.

Olesti, O. (2010). "Urbanització, integració i gestió del territori al nord-est de la península Ibèrica en època republicana (segles II-I aC)". En: Time of changes. In the beginning of the Romanization. Studies on the Rural World in the Roman Period, 5. Girona: Laboratori d'Arqueologia i Prehistoria de la Universitat de Girona, pp. 11-59.

Palencia, J. F. y Rodríguez, D. (2014). "La cerámica de barniz negro itálica en el territorium de la antigua ciudad romana de Consabura (Consuegra, Toledo)". Lucentum, XXXIII, pp. 113-122. DOI: https://doi.org/10.14198/lvcentvm2014.33.06

Pasquinucci, M., Alessi, D., Bianchini, S., Cibecchini, F., Cherubini, L., Del Rio, A., Menchelli, S., Spienesi, P., Vallebona, M. y Capelli, C. (1998). "Ceramica a vernice nera dall'Etruria settentrionale costiera. Primo contributo alla caratterizzazione delle produzioni locali e delle importazioni". En: Frontini, P. M. y Grassi T. (Eds.). Indagini archeometriche relative alla ceramica a vernice nera: nuovi dati sulla provenienza e sulla diffusione, Atti del seminario Internazione di Studio. Milano 22-23 noviembre 1996. Como: Edizioni New Press, pp. 101-111.

Pedroni, L. (1986). Ceramica a vernice nera da Cales. Napoli: Ligouri editore.

Pedroni, L. (2001). Ceramica calena a vernice nera. Produzione e diffusione. Città di Castello: Petruzzi editore.

Picon, M. (1988). "Sur l'origine de quelques groupes de céramiques d'Olbia: céramiques à vernis noir, céramiques de cuisine, céramiques à pâte claire”. En: Bats, M. (Ed.). Vaisselle et alimentation à Olbia de Provence (v. 350-v. 50 av. J.-C.). Revue archéologique de Narbonnaise, $18^{\mathrm{e}}$ suppl., pp. 249-265.

Picon, M. y Thirion-Merle, V. (2002). "Céramiques à vernis noir de La Loba, altérations et origines". En: Blasquez Martinez, J. M., Sillieres, P. y Domergue, C. (Eds.). La Loba (Fuenteobejuana, Cordoue, Espagne), La mine et le village minier antiques. Mémoires, 7. Bordeaux: $\mathrm{Au}-$ sonius, pp. 289-293.

Picon, M., Vichy, M. y Chapotat, G. (1971). "Note sur la composition des céramiques campaniennes de type A et B". Rei Cretariae Romanae Fautores Acta, 13, pp. 82-88.

Principal, J. y Ribera, A. (2013). "El material más apreciado por los arqueólogos. La cerámica fina. La cerámica de barniz negro". Manual de cerámica romana. Del mundo Helenístico al Imperio Romano. Alcalá de Henares, Museo Arqueológico Regional; Madrid: Colegio Oficial de Doctores y Licenciados en Filosofía y Letras y en Ciencias, Sección de Arqueología, pp. 43-146. 
R CORE TEAM (2017). R: A language and environment for statistical computing. Vienna: R Foundation for Statistical Computing. Disponible en: http://www.R-project.org [Consultado 20-01-2019].

Sanmarti-Grego, E. (1978). La Ceramica campaniense de Emporion y Rhode. Monografies Emporitanes, IV. Barcelona: Museu d'Arqueologia de Catalunya.

Sanmartí, E., Barberà, J., Castanyer, P. y Tremoleda, J. (1986). "Las estructuras griegas de los siglos V y VI a. de J. C. halladas en el sector sur de la necrópolis de Ampurias (campaña de excavaciones del año 1986)". Cuadernos de prehistoria y arqueología castellonenses, 12, pp. 141-218.

Sanmartí i Greco, E., Castanyer, P. y Tremoleda i Trilla, J. (1989). "Darreres excavacions a Empúries. El sector meridional de la neàpolis". Tribuna d'Arqueologia, 1988-1989, pp. 79-88. Disponible en: http://hdl.handle. net/10687/91449 [Consultado 26-11-2020].

Sanmarti, J., Principal, J., Trias, M. G. y Orfila, M. (1996). Les ceràmiques de vernis negre de Pollentia. The William $\mathrm{L}$. Bryant Foundation, 5. Barcelona: Publicacions UB.

Schwedt, A., Mommsen, H., Zacharias, N. y Buxeda i Garrigós, J. (2006). "Analcime crystallization and compositional profiles - comparing approaches to detect post-depositional alterations in archaeological pottery". Archaeometry, 48, pp. 237-251. DOI: https://doi.org/10.1111/j.1475-4754.2006.00254.x

Shannon, C. E. (1948). "A Mathematical Theory of Communication". The Bell System Technical Journal, 27 (3), pp. 379-423. DOI: https://doi.org/10.1002/j.1538-7305.1948.tb01338.x

Sinner, A. G. (2017). La ceca de Ilduro. Archaeopress Roman Archaeology, 29. Oxford: Archaeopress Publishing Ltd.

Stannard, C. y Sinner, A. G. (2014). "A central Italian coin with «Dionysus/Panther» types from Cabrera de Mar
(El Maresme, Barcelona), and contacts between central Italy, Hispania Citerior and Hispania Ulterior in the 2nd and 1st centuries BC". Saguntum, 46, pp. 159-180. DOI: https://doi.org/10.7203/sagvntvm.46.2646

Tchernia, A. (2016). The Romans and trade. Oxford: Oxford University Press.

Temin, P. (2013). The Roman market economy. Princeton (NJ): Princeton University Press.

Tremoleda, J., Santos, M. y Castanyer, P. (2016). “Una nova fortificació d'època republicana a Empúries. Una base militar per a la conquista d'Hispània". Annals de l'Institut d'Estudis Empordanesos, 47, pp. 47-74.

Van de Boogaart, K. G. y Tolosana-Delgado, R. (2013). Analysing Compositional Data with R. Berlin, Heidelberg: Springer-Verlag.

Vendrell-Saz, M., Pradell, T., Molera, J. y Aliaga, S. (1991). "Proto-Campanian and A-Campanian ceramics: characterization of the differences between the Black coatings". Archaeometry, 33(1), pp. 109-117. DOI: https://doi.org/10.1111/j.1475-4754.1991.tb00689.x

Vivar, G. (2013). El derelicte d'Illa Pedrosa. Comerç marítim i xarxes de redistribució en època tardorrepublicana al Mediterrani centre-occidental, Tesis doctorals electròniques, Universitat de Barcelona. Disponible en: http://hdl.handle.net/10803/113555.

Zamora, D. (1995). Les Ceràmiques de vernís negre del poblat ibèric del Turó d'en Boscà, Badalona: aproximació a la interpretació històrico-arqueològica del poblat. Igualada: Arqueoanoia.

Zacharias, N., Schwedt, A., Buxeda, J., Michael, C. T., Mommsen, H. y Kilikoglou, V. (2007). "A contribution to the study of post-depositional alterations of pottery using TL dating analysis". Journal of Archaeological Science, 34 (11), pp. 1804-1809. DOI: https://doi.org/10.1016/j.jas.2006.12.017 